\title{
Synthesis and biological activity of amino acid conjugates of abscisic acid
}

Yasushi Todoroki ${ }^{\mathrm{a}, *}$, Kenta Narita ${ }^{\mathrm{a}}$, Taku Muramatsu ${ }^{\mathrm{a}}$, Hajime Shimomura ${ }^{\mathrm{a}}$, Toshiyuki

Ohnishi $^{\mathrm{b}}$, Masaharu Mizutani ${ }^{\mathrm{c}, \dagger}$, Kotomi Ueno ${ }^{\mathrm{a}, \uparrow}$, Nobuhiro Hirai $^{\mathrm{d}}$

${ }^{a}$ Department of Applied Biological Chemistry, Faculty of Agriculture, Shizuoka University, Shizuoka 422-8529, Japan

${ }^{b}$ Division of Global Research Leaders, Shizuoka University, 836 Ohya, Suruga-ku, Shizuoka 422-8529, Japan

${ }^{c}$ Institute for Chemical Research, Kyoto University, Uji, Kyoto 611-0011, Japan

${ }^{d}$ Division of Environmental Science and Technology, Graduate School of Agriculture, Kyoto University, Kyoto 606-8501, Japan

Keywords: Plant growth regulator; ABA; abscisic acid; amino acid conjugate; amidohydrolase

Abbreviations: ABA, abscisic acid; ABA-GE, abscisic acid glucosyl ester; GA, gibberellin; IAA, indoleacetic acid; JA, jasmonic acid; SA, salicylic acid; Me ABAmide, methyl abscisic amide.

* Corresponding author. Tel./fax: +81 542384871.

E-mail address: aytodor@ipc.shizuoka.ac.jp (Y. Todoroki)

${ }^{\dagger}$ Present address: Graduate School of Agricultural Science, Kobe University, Kobe 657-8501, Japan. 


\section{ABSTRACT}

We prepared 19 amino acid conjugates of the plant hormone abscisic acid (ABA) and investigated their biological activity, enzymatic hydrolysis by a recombinant Arabidopsis amidohydrolases GST-ILR1 and GST-IAR3, and metabolic fate in rice seedlings. Different sets of ABA-amino acids induced ABA-like responses in different plants. Some ABA-amino acids, including some that were active in bioassays, were hydrolyzed by recombinant Arabidopsis GST-IAR3, although GST-ILR1 did not show hydrolysis activity for any of the ABA-amino acids. ABA-L-Ala, which was active in all the bioassays, an Arabidopsis seed germination, spinach seed germination, and rice seedling elongation assays, except in a lettuce seed germination assay and was hydrolyzed by GST-IAR3, was hydrolyzed to free ABA in rice seedlings. These findings suggest that some plant amidohydrolases hydrolyze some ABA-amino acid conjugates. Because our study indicates the possibility that different plants have hydrolyzing activity toward different ABA-amino acids, an ABA-amino acid may function as a species-selective pro-hormone of ABA. 


\section{Introduction}

Abscisic acid (ABA) is a plant hormone involved in stress tolerance, stomatal closure, seed dormancy, and other physiological events. ${ }^{1-3}$ Endogenous levels of ABA in plants are cooperatively controlled by biosynthesis, transport, and catabolic inactivation in response to environmental changes. ABA catabolism includes two major pathways: hydroxylation and glucosyl conjugation (Fig. 1). The principal pathway is mediated by ABA 8'-hydroxylase $(\mathrm{CYP} 707 \mathrm{~A})^{4,5}$ to produce $8^{\prime}$-hydroxy-ABA, which is thermodynamically unstable and is spontaneously converted into the more stable tautomer phaseic acid. The $\mathrm{C} 1$ glucose conjugate $\mathrm{ABA}-\mathrm{GE}$ is a common metabolite in plants and the major ABA metabolite in some plants. ${ }^{6}$

Some acidic plant hormones, indoleacetic acid (IAA), jasmonic acid (JA), and salicylic acid (SA), are sometimes found as amino acid conjugates. ${ }^{7-9}$ Various amino acid conjugates are considered to be a storage form, a deactivated form, or an endogenous bioactive molecule, although no definite role has been established except for $(+)-7$-iso-JA-L-isoleucine. ${ }^{10}$ For other classical acidic plant hormones, gibberellin (GA) and ABA, there are no reports of amino acid conjugates being the endogenous metabolites, and based on research on $\mathrm{ABA}$ metabolism, we have never found any evidence that ABA-amino acid conjugates are endogenous metabolites. Moreover, ABA-amino acids have never been chemically synthesized, although $2 E$-ABA-L-serine was recently reported as a potential neuroprotective drug. ${ }^{11}$

Plants have amidohydrolase genes, some of which have been identified as IAA-amino acid conjugate hydrolases. ${ }^{12-17}$ LeClere et al. suggested the GST fusion of an IAA-amino acid hydrolase, GST-IAR3, may hydrolyze JA-amino acids, as well as IAA-amino acids, on the basis of their preliminary experiments, ${ }^{14}$ although amidohydrolases with specificity for JA-amino acids have not yet been identified. Because ABA is not so different in size and polarity from IAA and JA, these amidohydrolases might also hydrolyze ABA-amino acids. If different plant species have a different set of amidohydrolases with distinct substrate 
specificity, an ABA-amino acid may function as a species-selective ABA pro-hormone. Here we describe the synthesis and biological activity of 19 ABA-L-amino acid conjugates. We also describe the in vitro hydrolase activity of IAA-amino acid hydrolases for ABA-L-amino acids and the in vivo hydrolysis of ABA-L-Ala to release the free ABA.

\section{Results and Discussion}

\subsection{Synthesis}

The acid chloride 1 was prepared by reacting $S-(+)-A B A$ with phosphorus trichloride (Fig. 2). The coupling reaction of $\mathbf{1}$ and esters of standard L-amino acids except for L-arginine gave ABA-L-amino acid esters, which were hydrolyzed with sodium hydroxide or formic acid to afford ABA-L-amino acids. In the case of ABA-Ala only, the D-amino acid conjugate was also synthesized. The preparation of ABA-L-Arg was attempted but failed using a method similar to that for the other conjugates. Because ABA-L-Lys was difficult to isolate from the hydrolyzed residue of the methyl ester, it was used for enzyme and biological assays as the methyl ester. An ABA derivative with a simple amide moiety, methyl abscisic amide (Me ABAmide), was also prepared by reacting the acid chloride $\mathbf{1}$ with methylamine. Hexadeuterated labeled ABA-L-Ala and ABA-D-Ala for an in vivo hydrolysis assay were prepared by treatment of unlabeled compounds with $1 \mathrm{M}$ NaOD solution. The ABA-amino acids prepared were characterized by ESI-TOF-MS (Table 1) and ${ }^{1} \mathrm{H}$ NMR. ABA contamination of the conjugate samples was checked by reverse-phase HPLC analysis (Table 1). Even in the most contaminated sample, the ABA content was less than $0.1 \%$.

\subsection{Biological activity}


The biological activity of ABA-L-amino acids and ABA-D-Ala was examined by four bioassays: germination assays using Arabidopsis thaliana, lettuce and spinach seeds, and a rice seedling growth assay (Fig. 3). All the compounds were tested at the same concentration, $10 \mu \mathrm{M}$ in the Arabidopsis assay and $100 \mu \mathrm{M}$ in other assays, at which the inhibitory ratio of ABA was $100 \%$. Some L-amino acid conjugates showed significant activity, especially in the rice growth assay; seven conjugates, ABA-Gly, ABA-L-Ala, ABA-L-Met, ABA-L-Ser, ABA-L-Asn, ABA-L-Gln, and ABA-L-Asp, exhibited more than $80 \%$ inhibition of rice seedling elongation. The dose response effect of these conjugates was examined and $\mathrm{IC}_{50}$ values were determined to be 6 to $16 \mu \mathrm{M}$ (Table 2), indicating that their activity is almost equivalent to that of ABA. On the other hand, in contrast to ABA-L-Ala, ABA-D-Ala showed no significant activity. In germination assays, the effect of ABA-amino acids was generally weaker than in the rice growth assay. In the Arabidopsis assay, ABA-L-Ala and ABA-L-Lys inhibited germination, whereas in the spinach assay, ABA-L-Asp, ABA-L-Glu, and ABA-L-Gln functioned as relatively effective inhibitors. These observations allowed us to conclude that the activity of ABA-amino acid conjugates is different in different species.

There are three possibilities for specific conjugates exhibiting ABA-like activity: (1) the conjugates themselves act as ABA mimics; (2) free ABA was released by nonenzymatic hydrolysis of the conjugates owing to their chemical instability; and (3) free ABA was released by enzymatic hydrolysis of the conjugates. The first possibility is not plausible, because the free carboxylate group of ABA is significantly involved in ABA activity, ${ }^{18}$ and the crystal structure of the ABA receptor bound with ABA shows that the carboxylate of ABA forms an ion pair with the $\varepsilon$-amino group of the lysine residue at the bottom of the binding cavity. ${ }^{19-23}$ To investigate the second possibility, we examined the stability of the active conjugates under the rice assay conditions. ABA-L-Ala was not decomposed to release free ABA by incubation in an aqueous solution at $25^{\circ} \mathrm{C}$ for 7 days under continuous light conditions, although it may have partially isomerized into 2E-ABA-L-Ala (not identified) (Fig. 4). The other active conjugates also were stable in the aqueous solution. Therefore, the second 
possibility is also not plausible. The active ABA-amino acids may have been enzymatically hydrolyzed to release free ABA after incorporation in plants.

\subsection{Enzymatic amidohydrolysis}

We expressed two GST fusions of Arabidopsis IAA-amino acid hydrolases, GST-IAR3 and GST-ILR1, according to a reported method ${ }^{14}$ to examine whether the ABA-amino acids are enzymatically hydrolyzed by plant amidohydrolases. After checking that these GST-hydrolase fusions hydrolyzed IAA-L-Ala as reported, ABA-amino acid hydrolysis activity was examined. GST-ILR1 did not show hydrolysis activity for any of the ABA-amino acids, whereas GST-IAR3 hydrolyzed four ABA-L-amino acids, ABA-L-Gly, ABA-L-Ala, ABA-L-Met, and ABA-L-Asn, although activity was lower than that for IAA-L-Ala (Table 3). ABA-D-Ala was not hydrolyzed by GST-IAR3. The ABA-L-amino acids hydrolyzed by GST-IAR3 coincide with the corresponding IAA-amino acids hydrolyzed by the same enzyme, ${ }^{14}$ meaning the activity is probably dependent on the amino acid preference of GST-IAR3. TaIAR3, an ortholog for the Arabidopsis IAR3, hydrolyzes the amino acid

conjugates of indole-3-butyric acid. ${ }^{15}$ These findings indicate that some IAA amidohydrolases may primarily recognize the amino acid part of conjugates rather than IAA. Rice (Oryza sativa) has a homolog (Os01g0560000) of Arabidopsis IAR3, and other related genes. Lettuce (Lactuca sativa) also has genes homologous to ILR1 and IAR3. ${ }^{24}$

This result indicates that ABA-amino acids exhibit the biological activity of ABA after enzymatic hydrolyzation. However, the bioactive ABA-amino acids in the Arabidopsis assay do not completely coincide with ABA-amino acids hydrolyzed by Arabidopsis GST-IAR3. This inconsistency may suggest that other amidohydrolases are responsible for ABA-amino acid hydrolysis in Arabidopsis seeds. In addition, uptake efficiency may be involved in the efficiency of in vivo hydrolysis of ABA-amino acids. The difference in the activity of ABA-amino acids in different bioassays may depend on differential expression or distinct amidohydrolase combinations. 


\subsection{Rice seedlings hydrolyze ABA-L-Ala, but not ABA-D-Ala, to release free ABA}

To test whether the active ABA-amino acids are hydrolyzed in plants, ABA- $d_{6}$-L-Ala and ABA- $d_{6}$-D-Ala were fed to 3 -day-old rice seedlings for 4 days. The $80 \%$ acetone extracts of the seedlings were methylated with TMS-diazomethane for purification and analyzed by LC-MS in neutral conditions, in which $\mathrm{ABA}-d_{6}$ must be stable enough to not revert to the nondeuterated form. ABA- $d_{6}$ was detected only from seedlings administered ABA- $d_{6}$-L-Ala (Fig. 5). This means that rice seedlings hydrolyzed ABA-L-Ala, but not ABA-D-Ala, to release free ABA. This finding suggests that amidohydrolases in rice seedlings, just like Arabidopsis GST-IAR3, recognize an amide moiety originating from L-amino acids, not D-amino acids.

\section{Conclusions}

We prepared 19 ABA-amino acid conjugates and investigated their biological activity, enzymatic hydrolysis by recombinant Arabidopsis amidohydrolases, and metabolic fate in rice seedlings. Different sets of ABA-amino acids induced ABA-like responses in different plants. Some ABA-amino acids, partially including active ones in bioassays, were hydrolyzed by recombinant Arabidopsis GST-IAR3. ABA-L-Ala, which was active except in a lettuce bioassay and was hydrolyzed by GST-IAR3, was hydrolyzed to free ABA in rice seedlings. These findings suggest that some plant amidohydrolases, including those reported as IAA amidohydrolases, hydrolyze some ABA-amino acid conjugates. No ABA-amino acids have been identified from plant materials. We also have not yet investigated whether ABA-amino acids are endogenous metabolites in plants. Thus, it is not clear whether plants have specific amidohydrolases to ABA-amino acids. In our preliminary experiment, GA3-L-Ala, -Gly, -Met, and -Ile induced GA-like activity in rice seedlings (data not shown). Taken together, the substrate specificity of plant amidohydrolases may depend mainly on the amino acid part of 
the conjugate, not on the phytohormone part. Because our study indicates the possibility that different plants have hydrolyzing activity toward different ABA-amino acids, ABA-amino acids may function as a species-selective pro-hormone of ABA.

\section{Experimental}

\subsection{General}

${ }^{1} \mathrm{H}$ NMR spectra were recorded with tetramethylsilane as the internal standard using a JEOL JNM-EX270 (270 MHz) NMR spectrometer. High resolution mass spectra were obtained with a JEOL JMS-T100LC (AccuTOF). Column chromatography was performed on silica gel (Wakogel C-200). The purity of synthesized compounds was confirmed by HPLC using a Shimadzu LC-10. LC-MS analysis was performed by a Shimadzu LCMS-2010 system.

\subsection{Chemicals}

$(+)$-ABA was a gift from Toray Industries Inc., Tokyo, Japan. IAA-L-alanine was commercially purchased.

\subsection{Synthesis of ABA-amino acid conjugates}

Conjugates were typically synthesized by adding the methyl, ethyl or t-butyl ester of amino acids (3-5 eq.) to (+)-ABA chloride, followed by hydrolysis with $\mathrm{NaOH}$ or formic acid. Amino acid esters were prepared by stirring the commercially available ester hydrochloride and triethylamine (3-5 eq.) in dry DMF for $10 \mathrm{~min}$. The mixture was filtered through absorbent cotton to remove the resulting salt before adding it to (+)-ABA chloride. (+)-ABA chloride was prepared by stirring (+)-ABA and $\mathrm{PCl}_{3}$ (1.2-3 eq.) in dry $\mathrm{CH}_{2} \mathrm{Cl}_{2}$ for $1 \mathrm{~h}$. After 
adding the amino acid ester to $(+)$-ABA chloride, the reaction mixture was stirred for $1 \mathrm{~h}$. After adding water, the mixture was extracted with $\mathrm{CH}_{2} \mathrm{Cl}_{2}$. The organic layer was washed with brine, dried over $\mathrm{Na}_{2} \mathrm{SO}_{4}$, and concentrated in vacuo. The residual oil was purified by silica gel column chromatography with a stepwise gradient of hexane-EtOAc. Except for ABA-L-Asn, ABA-L-Gln, and ABA-L-Lys, 0.5-1 M NaOH was added to each ABA-amino acid conjugate ester dissolved in $\mathrm{MeOH}$. The mixture was stirred for 1-2 h. After acidifying with $1 \mathrm{M} \mathrm{HCl}$ to $\mathrm{pH}$ 2, the mixture was extracted with EtOAc. The organic layer was washed with brine, dried over $\mathrm{Na}_{2} \mathrm{SO}_{4}$, and concentrated in vacuo. The residual oil was purified by silica gel column chromatography with a stepwise gradient of hexane-EtOAc containing $1 \%$ $\mathrm{AcOH}$ to afford the ABA amino acid conjugate as a white solid. The esters of ABA-L-Asn and ABA-L-Gln were dissolved in formic acid and stirred for $3 \mathrm{~h}$. After adding satd. $\mathrm{NaHCO}_{3}$, the mixture was extracted with $\mathrm{CH}_{2} \mathrm{Cl}_{2}$. The organic layer was washed with brine, dried over $\mathrm{Na}_{2} \mathrm{SO}_{4}$, and concentrated in vacuo. The residual oil was purified by silica gel column chromatography with a stepwise gradient of $\mathrm{CHCl}_{3}-\mathrm{MeOH}$ containing $1 \% \mathrm{AcOH}$ to afford the corresponding ABA amino acid conjugate as a white solid. The methyl ester of ABA-L-Lys was not hydrolyzed.

\subsubsection{ABA-Gly}

Yield: $37 \% .{ }^{1} \mathrm{H}$ NMR (270 MHz, $\mathrm{CD}_{3} \mathrm{OD}$ ): $\delta 1.02$ and 1.05 (each $3 \mathrm{H}, \mathrm{s}, \mathrm{H}_{3}-8^{\prime}$ and $\left.\mathrm{H}_{3}-9^{\prime}\right)$ ), 1.93 and 2.01 (each $3 \mathrm{H}, \mathrm{s}, \mathrm{H}_{3}-6$ and $\mathrm{H}_{3}-7^{\prime}$ ), 2.17 and 2.54 (each $1 \mathrm{H}, \mathrm{d}, J=16.8 \mathrm{~Hz}, \mathrm{H}_{2}-5^{\prime}$ ), $3.92\left(2 \mathrm{H}, \mathrm{s}, \mathrm{H}-\mathrm{C}_{\alpha}-\mathrm{Gly}\right), 5.85$ and $5.91\left(\right.$ each $1 \mathrm{H}, \mathrm{s}, \mathrm{H}-2$ and $\left.\mathrm{H}-3^{\prime}\right), 6.16(1 \mathrm{H}, \mathrm{d}, J=16.2 \mathrm{~Hz}$, H-5), $7.76(1 \mathrm{H}, \mathrm{d}, J=16.2 \mathrm{~Hz}, \mathrm{H}-4)$.

\subsubsection{ABA-L-Ala}

Yield: 49\%. ${ }^{1} \mathrm{H}$ NMR (270 MHz, $\mathrm{CD}_{3} \mathrm{OD}$ ): $\delta 1.02$ and 1.05 (each $3 \mathrm{H}, \mathrm{s}, \mathrm{H}_{3}-8{ }^{\prime}$ and $\mathrm{H}_{3}-9^{\prime}$ ), $1.40\left(3 \mathrm{H}, \mathrm{d}, J=7.3 \mathrm{~Hz}, \mathrm{H}_{3}-\mathrm{C}_{\beta}-\mathrm{Ala}\right.$ ), 1.93 and 2.00 (each $3 \mathrm{H}, \mathrm{d}, J=1.2 \mathrm{~Hz}, \mathrm{H}_{3}-6$ and $\mathrm{H}_{3}-7^{\prime}$ ), 2.17 and $2.55\left(1 \mathrm{H}, \mathrm{d}, J=16.8 \mathrm{~Hz}, \mathrm{H}_{2}-5^{\prime}\right), 4.40\left(1 \mathrm{H}, \mathrm{m}, \mathrm{H}-\mathrm{C}_{\alpha}\right.$-Ala), 5.84 and 5.92 (each $1 \mathrm{H}, \mathrm{s}$, H-2 and H-3'), 6.14 (1H, d, $J=16.1 \mathrm{~Hz}, \mathrm{H}-5), 7.73$ (1H, d, $J=16.1 \mathrm{~Hz}, \mathrm{H}-4)$. 


\subsubsection{ABA-D-Ala}

Yield: 57\%. ${ }^{1} \mathrm{H}$ NMR (270 MHz, $\mathrm{CD}_{3} \mathrm{OD}$ ): $\delta 1.02$ and 1.05 (each $3 \mathrm{H}, \mathrm{s}, \mathrm{H}_{3}-8{ }^{\prime}$ and $\mathrm{H}_{3}-9^{\prime}$ ), $1.39\left(3 \mathrm{H}, \mathrm{d}, J=7.3 \mathrm{~Hz}, \mathrm{H}_{3}-\mathrm{C}_{\beta}-\mathrm{Ala}\right), 1.93$ and 2.00 (each 3H, d, $J=1.0 \mathrm{~Hz}, \mathrm{H}_{3}-6$ and 7'), 2.16 and 2.54 (each $\left.1 \mathrm{H}, \mathrm{d}, J=17.0 \mathrm{~Hz}, \mathrm{H}_{2}-5^{\prime}\right), 4.40\left(1 \mathrm{H}, \mathrm{m}, \mathrm{H}-\mathrm{C}_{\alpha}-\mathrm{Ala}\right), 5.84$ and 5.91 (each $1 \mathrm{H}, \mathrm{s}$, H-2 and H-3'), 6.15 (1H, d, $J=16.2 \mathrm{~Hz}, \mathrm{H}-5), 7.72$ (1H, d, $J=16.2 \mathrm{~Hz}, \mathrm{H}-4)$.

\subsubsection{ABA-L-Val}

Yield: 39\%. ${ }^{1} \mathrm{H}$ NMR (270 MHz, $\left.\mathrm{CD}_{3} \mathrm{OD}\right): \delta 0.97\left(6 \mathrm{H}, \mathrm{m}, \mathrm{H}_{3}-\mathrm{C}_{\gamma}-\mathrm{Val} \times 2\right), 1.02$ and 1.05 (each $3 \mathrm{H}, \mathrm{s}, \mathrm{H}_{3}-8^{\prime}$ and $\mathrm{H}_{3}-9^{\prime}$ ), 1.93 and 2.01 (each $3 \mathrm{H}, \mathrm{d}, J=1.3 \mathrm{~Hz}, \mathrm{H}_{3}-6$ and $\mathrm{H}_{3}-7^{\prime}$ ), 2.1-2.2 (2H, overlapped, H-5' and H-C $\beta$-Val), $2.54\left(1 \mathrm{H}, \mathrm{d}, J=16.8 \mathrm{~Hz}, \mathrm{H}-5^{\prime}\right), 4.35(1 \mathrm{H}, \mathrm{d}, J=5.6 \mathrm{~Hz}$, H-C $\alpha_{\alpha}-\mathrm{Val}$ ), 5.90 and 5.93 (each 1H, s, H-2 and H-3'), $6.14(1 \mathrm{H}, \mathrm{d}, J=16.2 \mathrm{~Hz}, \mathrm{H}-5), 7.74(1 \mathrm{H}$, $\mathrm{d}, J=16.2 \mathrm{~Hz}, \mathrm{H}-4)$.

\subsubsection{ABA-L-Leu}

Yield: $22 \% .{ }^{1} \mathrm{H}$ NMR (270 MHz, $\left.\mathrm{CD}_{3} \mathrm{OD}\right): \delta 0.94$ and 0.97 (each $3 \mathrm{H}, \mathrm{d}, J=6.2 \mathrm{~Hz}$, $\mathrm{H}_{3}-\mathrm{C}_{\delta^{-}}$-Leu $\times 2$ ), 1.02 and 1.05 (each $3 \mathrm{H}, \mathrm{s}, \mathrm{H}_{3}-8^{\prime}$ and $\mathrm{H}_{3}-9^{\prime}$ ), 1.5-1.8 (3H, overlapped, $\mathrm{H}_{-} \mathrm{C}_{\gamma^{-}}$ and $\mathrm{H}_{2}-\mathrm{C}_{\beta}$-Leu), 1.93 and 2.00 (each $3 \mathrm{H}, \mathrm{d}, J=1.3 \mathrm{~Hz}, \mathrm{H}_{3}-6$ and $\mathrm{H}_{3}-7^{\prime}$ ), 2.17 and 2.54 (each $\left.1 \mathrm{H}, \mathrm{d}, J=16.8 \mathrm{~Hz}, \mathrm{H}_{2}-5^{\prime}\right), 4.45$ (1H, m, H-C $\mathrm{\alpha}$-Leu), 5.86 and 5.91 (each 1H, m, H-2 and 3'), $6.14(1 \mathrm{H}, \mathrm{d}, J=16.2 \mathrm{~Hz}, \mathrm{H}-5), 7.73(1 \mathrm{H}, \mathrm{d}, J=16.2 \mathrm{~Hz}, \mathrm{H}-4)$.

\subsubsection{ABA-L-Ile}

Yield: $21 \% .{ }^{1} \mathrm{H}$ NMR $\left(270 \mathrm{MHz}\right.$, acetone- $\left.d_{6}\right): \delta$ 0.9-1.0 $\left(6 \mathrm{H}\right.$, overlapped, $\mathrm{H}_{3}-\mathrm{C}_{\gamma^{-}}$and $\mathrm{H}_{3}-\mathrm{C}_{\delta}$-Ile), 1.04 and 1.07 (each $3 \mathrm{H}, \mathrm{s}, \mathrm{H}_{3}-8^{\prime}$ and $\mathrm{H}_{3}-9^{\prime}$ ), 1.26 and 1.53 (each $1 \mathrm{H}, \mathrm{m}, \mathrm{H}_{2}-\mathrm{C}_{\gamma}$-Ile), 1.91 and 1.98 (each $3 \mathrm{H}$ overlapped $1 \mathrm{H}, \mathrm{s}, \mathrm{H}_{3}-6$ and $\mathrm{H}_{3}-7^{\prime}$, overlapped $\mathrm{H}_{-} \mathrm{C}_{\beta}-\mathrm{Ile}$ ), 2.14 and 2.54 (each $\left.1 \mathrm{H}, \mathrm{d}, J=16.8 \mathrm{~Hz}, \mathrm{H}-5^{\prime}\right), 4.40\left(1 \mathrm{H}, \mathrm{s}, \mathrm{HO}-1^{\prime}\right), 4.52(1 \mathrm{H}, \mathrm{dd}, J=8.6$ and $5.6 \mathrm{~Hz}$, H-C $\mathrm{C}_{\alpha}-\mathrm{Ile}$ ), 5.81 and 5.94 (each 1H, s, H-2 and 3'), $6.25(1 \mathrm{H}, \mathrm{d}, J=16.2 \mathrm{~Hz}, \mathrm{H}-5), 7.23(1 \mathrm{H}, \mathrm{d}$, $\left.J=8.6 \mathrm{~Hz}, \mathrm{HN}-\mathrm{C}_{\alpha}-\mathrm{Ile}\right), 8.08(1 \mathrm{H}, \mathrm{d}, J=16.2 \mathrm{~Hz}, \mathrm{H}-4)$. 


\subsubsection{ABA-L-Met}

Yield: 39\%. ${ }^{1} \mathrm{H}$ NMR (270 MHz, $\mathrm{CD}_{3} \mathrm{OD}$ ): $\delta 1.02$ and 1.05 (each $3 \mathrm{H}, \mathrm{s}, \mathrm{H}_{3}-8$ and $\mathrm{H}_{3}-9^{\prime}$ ), 1.93 and 2.01 (each $3 \mathrm{H}, \mathrm{d}, J=1.3 \mathrm{~Hz}, \mathrm{H}_{3}-6$ and $\left.\mathrm{H}_{3}-7^{\prime}\right), 2.09$ (3H, s, $\left.\mathrm{H}_{3}-\mathrm{C}_{\varepsilon}-\mathrm{Met}\right), 1.9-2.2(3 \mathrm{H}$, overlapped, $\mathrm{H}-5$ ' and $\left.\mathrm{H}_{2}-\mathrm{C}_{\beta}-\mathrm{Met}\right), 2.5-2.6$ (3H, overlapped, $\mathrm{H}-5{ }^{\prime}$ and $\left.\mathrm{H}_{2}-\mathrm{C}_{\gamma}-\mathrm{Met}\right), 4.57(1 \mathrm{H}, \mathrm{m}$, $\mathrm{H}-\mathrm{C}_{\alpha}-\mathrm{Met}$ ), 5.86 and 5.91 (each $1 \mathrm{H}, \mathrm{s}, \mathrm{H}-2$ and $\left.\mathrm{H}-3^{\prime}\right), 6.15(1 \mathrm{H}, \mathrm{d}, J=16.2 \mathrm{~Hz}, \mathrm{H}-5), 7.73$ $(1 \mathrm{H}, \mathrm{d}, J=16.2 \mathrm{~Hz}, \mathrm{H}-4)$.

\subsubsection{ABA-L-Pro}

Yield: $38 \%$. ${ }^{1} \mathrm{H}$ NMR (270 MHz, $\mathrm{CD}_{3} \mathrm{OD}$ ): $\delta 1.02$ and 1.05 (each $3 \mathrm{H}, \mathrm{s}, \mathrm{H}_{3}-8{ }^{\prime}$ and $\mathrm{H}_{3}-9^{\prime}$ ), 1.91 and 2.02 (each $3 \mathrm{H}, \mathrm{s}, \mathrm{H}_{3}-6$ and $\left.\mathrm{H}_{3}-7^{\prime}\right), 1.9-2.1$ and 2.27 (4H, m, $\mathrm{H}_{2}-\mathrm{C}_{\beta}$ - and $\mathrm{H}_{2}-\mathrm{C}_{\gamma}-$ Pro), 2.17 and $2.53\left(1 \mathrm{H}, \mathrm{d}, J=16.8 \mathrm{~Hz}, \mathrm{H}_{2}-5^{\prime}\right), 3.58$ (2H, m, $\left.\mathrm{H}_{2}-\mathrm{C}_{\delta}-\mathrm{Pro}\right), 4.45$ (1H, m, H-C ${ }_{\alpha}$-Pro), 5.90 and 6.02 (each 1H, s, H-2 and H-3'), $6.14(1 \mathrm{H}, \mathrm{d}, J=16.1 \mathrm{~Hz}, \mathrm{H}-5), 7.26(1 \mathrm{H}, \mathrm{d}, J=16.1$ $\mathrm{Hz}, \mathrm{H}-4)$.

\subsubsection{ABA-L-Phe}

Yield: $72 \%$. ${ }^{1} \mathrm{H}$ NMR (270 MHz, $\mathrm{CD}_{3} \mathrm{OD}$ ): $\delta 1.01$ and 1.05 (each $3 \mathrm{H}, \mathrm{s}, \mathrm{H}_{3}-8$ ' and $\mathrm{H}_{3}-9^{\prime}$ ), 1.91 and 1.97 (each 3H, s, $\mathrm{H}_{3}-6$ and $\mathrm{H}_{3}-7^{\prime}$ ), 2.16 and 2.53 (each $1 \mathrm{H}, \mathrm{d}, J=16.8 \mathrm{~Hz}, \mathrm{H}_{2}-5^{\prime}$ ), $2.97\left(1 \mathrm{H}, \mathrm{dd}, J=13.9\right.$ and $\left.8.6 \mathrm{~Hz}, \mathrm{H}-\mathrm{C}_{\beta}-\mathrm{Phe}\right), 3.21$ (1H, dd, $J=13.9$ and $\left.5.3 \mathrm{~Hz}, \mathrm{H}-\mathrm{C}_{\beta}-\mathrm{Phe}\right)$, $4.68\left(1 \mathrm{H}, \mathrm{dd}, J=8.6\right.$ and $\left.5.3 \mathrm{~Hz}, \mathrm{H}-\mathrm{C}_{\alpha}-\mathrm{Phe}\right), 5.79(1 \mathrm{H}, \mathrm{s}, \mathrm{H}-2), 5.90\left(1 \mathrm{H}, \mathrm{s}, \mathrm{H}-3{ }^{\prime}\right), 6.13(1 \mathrm{H}, \mathrm{d}$, $J=16.2 \mathrm{~Hz}, \mathrm{H}-5), 7.1-7.3$ (5H, m, phenyl-Phe), 7.71 (1H, d, $J=16.2 \mathrm{~Hz}, \mathrm{H}-4)$.

\subsubsection{ABA-L-Trp}

Yield: 47\%. ${ }^{1} \mathrm{H}$ NMR (270 MHz, $\mathrm{CD}_{3} \mathrm{OD}$ ): $\delta 1.00$ and 1.04 (each $3 \mathrm{H}, \mathrm{s}, \mathrm{H}_{3}-8$ and $\mathrm{H}_{3}-9^{\prime}$ ), 1.90 and 1.96 (each $3 \mathrm{H}, \mathrm{d}, J=1.2 \mathrm{~Hz}, \mathrm{H}_{3}-6$ and $\mathrm{H}_{3}-7^{\prime}$ ), 2.16 and 2.53 (each $1 \mathrm{H}, \mathrm{d}, J=16.8 \mathrm{~Hz}$, $\left.\mathrm{H}_{2}-5^{\prime}\right), 3.18\left(1 \mathrm{H}, \mathrm{dd}, J=14.5\right.$ and $\left.7.6 \mathrm{~Hz}, \mathrm{H}-\mathrm{C}_{\beta}-\operatorname{Trp}\right), 3.36(1 \mathrm{H}, \mathrm{dd}, J=14.5$ and $5.3 \mathrm{~Hz}$, H-C $\left.\mathrm{C}_{\beta}-\operatorname{Trp}\right), 4.76\left(1 \mathrm{H}, \mathrm{m}, \mathrm{H}-\mathrm{C}_{\alpha}-\operatorname{Trp}\right), 5.79$ and 5.89 (each 1H, s, H-2 and H-3'), $6.13(1 \mathrm{H}, \mathrm{d}, J$ 
$=16.2 \mathrm{~Hz}, \mathrm{H}-5), 6.9-7.1,7.31$ and $7.55(5 \mathrm{H}$, overlapped, indolyl-Trp $), 7.73(1 \mathrm{H}, \mathrm{d}, J=16.2$ Hz, H-4), 10.25 (1H, m, HN-indolyl-Trp).

\subsubsection{ABA-L-Ser}

Yield: 38\%. ${ }^{1} \mathrm{H}$ NMR (270 MHz, $\mathrm{CD}_{3} \mathrm{OD}$ ): $\delta 1.02$ and 1.05 (each $3 \mathrm{H}, \mathrm{s}, \mathrm{H}_{3}-8{ }^{\prime}$ and $\mathrm{H}_{3}-9^{\prime}$ ), 1.92 and 2.00 (each $3 \mathrm{H}, \mathrm{d}, J=1.3 \mathrm{~Hz}, \mathrm{H}_{3}-6$ and $\left.\mathrm{H}_{3}-7^{\prime}\right), 2.17$ and $2.54(1 \mathrm{H}, \mathrm{d}, J=16.8 \mathrm{~Hz}$, $\left.\mathrm{H}_{2}-5^{\prime}\right), 3.83$ and 3.91 (each $1 \mathrm{H}, \mathrm{dd}, J=11.2$ and $4.2 \mathrm{~Hz}, \mathrm{H}_{2}-\mathrm{C}_{\beta}-\mathrm{Ser}$ ), $4.52(1 \mathrm{H}, \mathrm{dd}, J=4.9$ and $\left.4.2 \mathrm{~Hz}, \mathrm{H}-\mathrm{C}_{\alpha}-\mathrm{Trp}\right), 5.91$ (2H, s, H-2 and H-3'), 6.16 (1H, d, J=16.2 Hz, H-5), 7.76 (1H, d, J $=16.2 \mathrm{~Hz}, \mathrm{H}-4)$.

\subsubsection{ABA-L-Thr}

Yield: 43\%. ${ }^{1} \mathrm{H}$ NMR (270 MHz, $\mathrm{CD}_{3} \mathrm{OD}$ ): $\delta 1.02$ and 1.05 (each $3 \mathrm{H}, \mathrm{s}, \mathrm{H}_{3}-8{ }^{\prime}$ and $\mathrm{H}_{3}-9^{\prime}$ ), $1.19\left(3 \mathrm{H}, \mathrm{d}, J=6.6 \mathrm{~Hz}, \mathrm{H}_{3}-\mathrm{C}_{\gamma}-\mathrm{Thr}\right.$ ), 1.93 and 2.02 (each $3 \mathrm{H}, \mathrm{d}, J=1.3 \mathrm{~Hz}, \mathrm{H}_{3}-6$ and $\mathrm{H}_{3}-7^{\prime}$ ), 2.17 and 2.54 (each $\left.1 \mathrm{H}, \mathrm{d}, J=16.8 \mathrm{~Hz}, \mathrm{H}_{2}-5^{\prime}\right), 4.32\left(1 \mathrm{H}, \mathrm{m}, \mathrm{H}-\mathrm{C}_{\beta}-\mathrm{Thr}\right), 4.45(1 \mathrm{H}, \mathrm{d}, J=3.3$ Hz, H-C $\alpha_{\alpha}$ Thr), 5.90 and 5.95 (each 1H, s, H-2 and H-3'), 6.16 (1H, d, J=16.2 Hz, H-5), 7.76 $(1 \mathrm{H}, \mathrm{d}, J=16.2 \mathrm{~Hz}, \mathrm{H}-4)$.

\subsubsection{ABA-L-Asn}

Yield: $18 \%$. ${ }^{1} \mathrm{H}$ NMR (270 MHz, $\mathrm{CD}_{3} \mathrm{OD}$ ): $\delta 1.02$ and 1.06 (each $3 \mathrm{H}, \mathrm{s}, \mathrm{H}_{3}-8^{\prime}$ and $\mathrm{H}_{3}-9^{\prime}$ ), 1.93 and 2.00 (each 3H, s, $\mathrm{H}_{3}-6$ and $\left.\mathrm{H}_{3}-7^{\prime}\right), 2.17$ and $2.54\left(1 \mathrm{H}, \mathrm{d}, J=16.8 \mathrm{~Hz}, \mathrm{H}-5^{\prime}\right), 2.77$ (2H, m, $\left.\mathrm{H}_{2}-\mathrm{C}_{\beta}-\mathrm{Asn}\right), 4.72\left(1 \mathrm{H}, \mathrm{m}, \mathrm{H}-\mathrm{C}_{\alpha}-\mathrm{Asn}\right), 5.84$ and 5.91 (each $1 \mathrm{H}, \mathrm{s}, \mathrm{H}-2$ and $\mathrm{H}-3$ '), $6.15(1 \mathrm{H}$, d, $J=16.2 \mathrm{~Hz}, \mathrm{H}-5), 7.74(1 \mathrm{H}, \mathrm{d}, J=16.2 \mathrm{~Hz}, \mathrm{H}-4)$.

\subsubsection{ABA-L-GIn}

Yield: 35\%. ${ }^{1} \mathrm{H}$ NMR (270 MHz, $\mathrm{CD}_{3} \mathrm{OD}$ ): $\delta 1.02$ and 1.05 (each $3 \mathrm{H}, \mathrm{s}, \mathrm{H}_{3}-8$ and $\mathrm{H}_{3}-9^{\prime}$ ), 1.92 and 2.00 (each $3 \mathrm{H}, \mathrm{d}, J=1.0 \mathrm{~Hz}, \mathrm{H}_{3}-6$ and $\left.\mathrm{H}_{3}-7^{\prime}\right), 2.17\left(1 \mathrm{H}, \mathrm{d}, J=16.2 \mathrm{~Hz}, \mathrm{H}-5^{\prime}\right)$, 1.9-2.3 (4H, m, $\mathrm{H}_{2}-\mathrm{C}_{\beta^{-}}$and $\left.\mathrm{H}_{2}-\mathrm{C}_{\gamma^{-}} \mathrm{Gln}\right), 2.55\left(1 \mathrm{H}, \mathrm{d}, J=16.8 \mathrm{~Hz}, \mathrm{H}-5^{\prime}\right), 4.40(1 \mathrm{H}, \mathrm{m}$, 
H-C $\alpha_{\alpha}-\mathrm{Gln}$ ), 5.86 and 5.90 (each 1H, s, H-2 and H-3'), 6.15 (1H, d, J = 16.2 Hz, H-5), 7.73 (1H, $\mathrm{d}, J=16.2 \mathrm{~Hz}, \mathrm{H}-4)$.

\subsubsection{ABA-L-Tyr}

Yield: 43\%. ${ }^{1} \mathrm{H}$ NMR (270 MHz, $\mathrm{CD}_{3} \mathrm{OD}$ ): $\delta 1.01$ and 1.05 (each $3 \mathrm{H}, \mathrm{s}, \mathrm{H}_{3}-8$ ' and $\mathrm{H}_{3}-9^{\prime}$ ), 1.91 and 1.98 (each $3 \mathrm{H}, \mathrm{d}, J=1.3 \mathrm{~Hz}, \mathrm{H}_{3}-6$ and $\mathrm{H}_{3}-7^{\prime}$ ), 2.16 and 2.53 (each $1 \mathrm{H}, \mathrm{d}, J=16.8 \mathrm{~Hz}$, $\left.\mathrm{H}_{2}-5^{\prime}\right), 2.88\left(1 \mathrm{H}, \mathrm{dd}, J=13.9\right.$ and $\left.8.6 \mathrm{~Hz}, \mathrm{H}-\mathrm{C}_{\beta}-\mathrm{Tyr}\right), 3.10(1 \mathrm{H}, \mathrm{dd}, J=13.9$ and $5.6 \mathrm{~Hz}$, H-C $\mathrm{C}_{\beta}$-Tyr), $4.61\left(1 \mathrm{H}, \mathrm{dd}, J=8.6\right.$ and $5.6 \mathrm{~Hz}, \mathrm{H}-\mathrm{C}_{\alpha}-\mathrm{Tyr}$ ), 5.81 and 5.90 (each $1 \mathrm{H}, \mathrm{s}, \mathrm{H}-2$ and H-3'), 6.13 (1H, d, $J=16.5 \mathrm{~Hz}, \mathrm{H}-5), 6.69$ and 7.03 (each 2H, m, phenyl-Tyr), 7.70 (1H, d, $J$ $=16.5 \mathrm{~Hz}, \mathrm{H}-4)$.

\subsubsection{ABA-L-Cys}

Yield: 30\%. ${ }^{1} \mathrm{H}$ NMR (270 MHz, $\mathrm{CD}_{3} \mathrm{OD}$ ): $\delta 1.03$ and 1.06 (each $3 \mathrm{H}, \mathrm{s}, \mathrm{H}_{3}-8$ and $\mathrm{H}_{3}-9^{\prime}$ ), 1.93 and 2.01 (each $3 \mathrm{H}, \mathrm{s}, \mathrm{H}_{3}-6$ and $\mathrm{H}_{3}-7^{\prime}$ ), 2.17 and 2.55 (each $1 \mathrm{H}, \mathrm{d}, J=17.1 \mathrm{~Hz}, \mathrm{H}_{2}-5^{\prime}$ ), $3.11\left(1 \mathrm{H}, \mathrm{dd}, J=15.2\right.$ and $\left.7.3 \mathrm{~Hz}, \mathrm{H}-\mathrm{C}_{\beta}-\mathrm{Cys}\right), 2.8-3.1\left(1 \mathrm{H}, \mathrm{m}, \mathrm{H}-\mathrm{C}_{\beta}-\mathrm{Cys}\right), 4.5-4.6(1 \mathrm{H}, \mathrm{m}$,

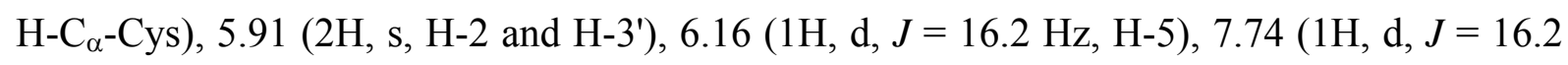
$\mathrm{Hz}, \mathrm{H}-4)$.

\subsubsection{ABA-L-Lys-Me}

Yield: 40\%. ${ }^{1} \mathrm{H}$ NMR (270 MHz, $\mathrm{CD}_{3} \mathrm{OD}$ ): $\delta 1.02$ and 1.06 (each $3 \mathrm{H}, \mathrm{s}, \mathrm{H}_{3}-8$ ' and $\mathrm{H}_{3}-9^{\prime}$ ), 1.2-1.8 (6H, m, $\mathrm{H}_{2}-\mathrm{C}_{\beta^{-}}, \mathrm{H}_{2}-\mathrm{C}_{\gamma^{-}}, \mathrm{H}_{2}-\mathrm{C}_{\delta^{-}}$Lys), 2.92 (2H, m, $\left.\mathrm{H}_{2}-\mathrm{C}_{\varepsilon}-\mathrm{Lys}\right), 1.93$ and 2.01 (each 3H, s, $\mathrm{H}_{3}-6$ and $\left.\mathrm{H}_{3}-7^{\prime}\right), 2.17$ and 2.54 (each $\left.1 \mathrm{H}, \mathrm{d}, J=16.8 \mathrm{~Hz}, \mathrm{H}_{2}-5^{\prime}\right), 3.72(3 \mathrm{H}, \mathrm{s}$, $\mathrm{H}_{3} \mathrm{COC}(\mathrm{O})$-Lys), 4.41 (1H, m, H-C ${ }_{\alpha}$-Lys), 5.89 and 5.91 (each 1H, s, H-2 and H-3'), $6.16(1 \mathrm{H}$, d, $J=16.2 \mathrm{~Hz}, \mathrm{H}-5), 7.72(1 \mathrm{H}, \mathrm{d}, J=16.2 \mathrm{~Hz}, \mathrm{H}-4)$.

\subsubsection{ABA-L-His}

Yield: $38 \%$. ${ }^{1} \mathrm{H}$ NMR (270 MHz, $\mathrm{CD}_{3} \mathrm{OD}$ ): $\delta 1.01$ and 1.05 (each $3 \mathrm{H}, \mathrm{s}, \mathrm{H}_{3}-8$ ' and $\mathrm{H}_{3}-9^{\prime}$ ), 1.92 and 1.99 (each $3 \mathrm{H}, \mathrm{s}, \mathrm{H}_{3}-6$ and $\mathrm{H}_{3}-7^{\prime}$ ), 2.17 and 2.53 (each $1 \mathrm{H}, \mathrm{d}, J=16.8 \mathrm{~Hz}, \mathrm{H}_{2}-5^{\prime}$ ), 
$3.11\left(1 \mathrm{H}, \mathrm{dd}, J=15.2\right.$ and $\left.7.3 \mathrm{~Hz}, \mathrm{H}-\mathrm{C}_{\beta}-\mathrm{His}\right), 3.25\left(1 \mathrm{H}, \mathrm{m}, \mathrm{H}-\mathrm{C}_{\beta}-\mathrm{His}\right), 4.63(1 \mathrm{H}, \mathrm{m}$, $\mathrm{H}-\mathrm{C}_{\alpha}$-His), 5.84 and 5.90 (each 1H, s, H-2 and H-3'), 6.14 (1H, d, J=16.2 Hz, H-5), 7.26 and 8.63 (each $1 \mathrm{H}, \mathrm{s}, \mathrm{H}-\mathrm{C}_{\delta^{-}}$and $\left.\mathrm{H}-\mathrm{C}_{\varepsilon^{-}}-\mathrm{His}\right), 7.71(1 \mathrm{H}, \mathrm{d}, J=16.2 \mathrm{~Hz}, \mathrm{H}-4)$.

\subsubsection{ABA-L-Asp}

Yield: 57\%. ${ }^{1} \mathrm{H}$ NMR (270 MHz, $\mathrm{CD}_{3} \mathrm{OD}$ ): $\delta 1.02$ and 1.06 (each $3 \mathrm{H}, \mathrm{s}, \mathrm{H}_{3}-8$ and $\mathrm{H}_{3}-9^{\prime}$ ), 1.93 and 2.00 (each $3 \mathrm{H}, \mathrm{d}, J=1.3 \mathrm{~Hz}, \mathrm{H}_{3}-6$ and $\mathrm{H}_{3}-7^{\prime}$ ), 2.17 and 2.54 (each $1 \mathrm{H}, \mathrm{d}, J=16.8 \mathrm{~Hz}$, $\left.\mathrm{H}_{2}-5^{\prime}\right), 2.83$ (2H, m, $\left.\mathrm{H}_{2}-\mathrm{C}_{\beta}-\mathrm{Asp}\right), 4.76$ (1H, m, H-C $\left.\alpha^{-}-\mathrm{Asp}\right), 5.85$ and 5.91 (each 1H, s, H-2 and H-3'), 6.16 (1H, d, $J=16.2 \mathrm{~Hz}, \mathrm{H}-5), 7.76$ (1H, d, $J=16.2 \mathrm{~Hz}, \mathrm{H}-4)$.

\subsubsection{ABA-L-Glu}

Yield: 15\%. ${ }^{1} \mathrm{H}$ NMR (270 MHz, $\mathrm{CD}_{3} \mathrm{OD}$ ): $\delta 1.02$ and 1.05 (each $3 \mathrm{H}, \mathrm{s}, \mathrm{H}_{3}-8{ }^{\prime}$ and $\mathrm{H}_{3}-9^{\prime}$ ), 1.93 and 2.00 (each $3 \mathrm{H}, \mathrm{d}, J=1.3 \mathrm{~Hz}, \mathrm{H}_{3}-6$ and $\left.\mathrm{H}_{3}-7^{\prime}\right), 1.9-2.2(3 \mathrm{H}$, overlapped, $\mathrm{H}-5$ ' and $\left.\mathrm{H}_{2}-\mathrm{C}_{\beta}-\mathrm{Glu}\right), 2.40\left(2 \mathrm{H}, \mathrm{m}, \mathrm{H}_{2}-\mathrm{C}_{\gamma}-\mathrm{Glu}\right), 2.55\left(1 \mathrm{H}, \mathrm{d}, J=16.8 \mathrm{~Hz}, \mathrm{H}-5{ }^{\prime}\right), 4.44(1 \mathrm{H}, \mathrm{m}$, H-C $\alpha_{\alpha}-\mathrm{Glu}$ ), 5.86 and 5.91 (each 1H, s, H-2 and H-3'), $6.15(1 \mathrm{H}, \mathrm{d}, J=16.2 \mathrm{~Hz}, \mathrm{H}-5), 7.73(1 \mathrm{H}$, $\mathrm{d}, J=16.2 \mathrm{~Hz}, \mathrm{H}-4)$.

\subsubsection{ABA- $\mathrm{d}_{6}$-L-Ala and -D-Ala}

A solution of ABA-L-Ala $(7.0 \mathrm{mg}, 21 \mu \mathrm{mol})$ in $\mathrm{D}_{2} \mathrm{O}(0.5 \mathrm{ml})$ was stirred, and $1 \mathrm{M} \mathrm{NaOD}$ $(1.5 \mathrm{ml})$ was added; the mixture was stirred for $70 \mathrm{~h}$ at room temp. in the dark. After quenching with $1 \mathrm{M} \mathrm{DCl}(2 \mathrm{ml})$, the mixture was extracted with EtOAc. The organic layer was washed with $\mathrm{D}_{2} \mathrm{O}$, dried over $\mathrm{Na}_{2} \mathrm{SO}_{4}$, and concentrated in vacuo. The residual oil was purified by silica gel column chromatography with a stepwise gradient of hexane-EtOAc to give ABA- $d_{6}$-L-Ala $\left(3.0 \mathrm{mg}, 8.8 \mu \mathrm{mol}, 42 \%\right.$ yield) as a pale yellow oil. ${ }^{1} \mathrm{H}$ NMR $(270 \mathrm{MHz}$, $\mathrm{CD}_{3} \mathrm{OD}$ ): $\delta 1.02$ and 1.05 (each $3 \mathrm{H}, \mathrm{s}, \mathrm{H}_{3}-8^{\prime}$ and $\left.9^{\prime}\right), 1.39\left(3 \mathrm{H}, \mathrm{d}, J=7.3 \mathrm{~Hz}, \mathrm{H}_{3}-3^{\prime \prime}\right), 2.00(3 \mathrm{H}$, d, $\left.J=1.0 \mathrm{~Hz}, \mathrm{H}_{3}-6\right), 4.39$ (1H, q, $\left.J=7.3 \mathrm{~Hz}, \mathrm{H}-2 "\right), 5.84(1 \mathrm{H}, \mathrm{s}, \mathrm{H}-2), 6.14(1 \mathrm{H}, \mathrm{d}, J=16.2$ $\mathrm{Hz}, \mathrm{H}-5), 7.73(1 \mathrm{H}, \mathrm{d}, J=16.2 \mathrm{~Hz}, \mathrm{H}-4)$. ESI-TOF-MS (positive): $[\mathrm{M}+\mathrm{Na}]^{+}$at $\mathrm{m} / \mathrm{z} 364.2007$ $\left(\mathrm{C}_{18} \mathrm{H}_{19} \mathrm{D}_{6} \mathrm{NO}_{5} \mathrm{Na}\right.$ requires 364.2007$)$. 
A similar approach for ABA-D-Ala $(19.0 \mathrm{mg}, 57 \mu \mathrm{mol})$ gave ABA- $d_{6}$-D-Ala $(17.0 \mathrm{mg}, 50$ $\mu \mathrm{mol}, 88 \%$ yield) as a pale yellow oil. ${ }^{1} \mathrm{H}$ NMR (270 MHz, $\left.\mathrm{CD}_{3} \mathrm{OD}\right): \delta 1.02$ and 1.05 (each $3 \mathrm{H}, \mathrm{s}, \mathrm{H}_{3}-8^{\prime}$ and 9'), $1.39\left(3 \mathrm{H}, \mathrm{d}, J=7.3 \mathrm{~Hz}, \mathrm{H}_{3}-3^{\prime \prime}\right), 2.00\left(3 \mathrm{H}, \mathrm{s}, \mathrm{H}_{3}-6\right), 4.40(1 \mathrm{H}, \mathrm{q}, J=7.3$ Hz, H-2"), 5.84 (1H, s, H-2), 6.15 (1H, d, $J=16.0 \mathrm{~Hz}, \mathrm{H}-5), 7.72(1 \mathrm{H}, \mathrm{d}, J=16.0 \mathrm{~Hz}, \mathrm{H}-4)$; ESI-TOF-MS (positive): [M+Na $]^{+}$at $\mathrm{m} / \mathrm{z} 364.2004\left(\mathrm{C}_{18} \mathrm{H}_{19} \mathrm{D}_{6} \mathrm{NO}_{5} \mathrm{Na}\right.$ requires 364.2007).

\subsubsection{ABA-methyl amide}

ABA methyl-amide was prepared by the similar manner as the preparation of ABA-amino acid conjugates. After adding methyl amine (2.0 M THF solution, $250 \mu \mathrm{l}, 500 \mu \mathrm{mol})$ in THF $(1.5 \mathrm{ml})$ to $(+)$-ABA chloride prepared from $(+)$-ABA $(30 \mathrm{mg}, 114 \mu \mathrm{mol})$ in $\mathrm{CH}_{2} \mathrm{Cl}_{2}(1.5 \mathrm{ml})$ at room temperature, the reaction mixture was stirred for $0.8 \mathrm{~h}$. After adding water, the mixture was extracted with EtOAc. The organic layer was washed with brine, dried over $\mathrm{Na}_{2} \mathrm{SO}_{4}$, and concentrated in vacuo. The residual oil was purified by silica gel column chromatography with a stepwise gradient of hexane-EtOAc to afford ABA-methyl amide (20.3 mg, $73 \mu \mathrm{mol}, 64 \%$ ). ${ }^{1} \mathrm{H}$ NMR $\left(270 \mathrm{MHz}, \mathrm{CDCl}_{3}\right.$ ): $\delta 1.01$ and 1.10 (each $3 \mathrm{H}, \mathrm{s}, \mathrm{H}_{3}-8^{\prime}$ and $\left.9^{\prime}\right), 1.93\left(3 \mathrm{H}, \mathrm{d}, J=1.3 \mathrm{~Hz}, \mathrm{H}_{3}-6\right.$ or $\left.\mathrm{H}_{3}-7^{\prime}\right), 1.96\left(3 \mathrm{H} \mathrm{d}, J=1.3 \mathrm{~Hz}, \mathrm{H}_{3}-6\right.$ or $\left.\mathrm{H}_{3}-7^{\prime}\right), 2.28$ and 2.47 (each $\left.1 \mathrm{H}, \mathrm{d}, J=17.1 \mathrm{~Hz}, \mathrm{H}_{2}-5^{\prime}\right), 2.84\left(3 \mathrm{H}, \mathrm{d}, J=4.9 \mathrm{~Hz}, \mathrm{H}_{3} \mathrm{C}-\mathrm{NH}-\right), 5.64(1 \mathrm{H}, \mathrm{s}$, H-2 or H-3'), $5.79(1 \mathrm{H}, \mathrm{br}, \mathrm{HN}-), 5.91(1 \mathrm{H}, \mathrm{s}, \mathrm{H}-2$ or H-3'), $6.08(1 \mathrm{H}, \mathrm{d}, J=16.2 \mathrm{~Hz}, \mathrm{H}-5)$, $7.93(1 \mathrm{H}, \mathrm{d}, J=16.2 \mathrm{~Hz}, \mathrm{H}-4)$; ESI-TOF-MS (positive): $[\mathrm{M}+\mathrm{Na}]^{+}$at $\mathrm{m} / \mathrm{z} 300.1572$ $\left(\mathrm{C}_{16} \mathrm{H}_{23} \mathrm{NO}_{3} \mathrm{Na}\right.$ requires 300.1576$)$.

\subsection{Hydrolysis of ABA-amino acid conjugates by GST-IAR3 and GST-ILR1}

\subsubsection{Generation and purification of GST-IAR3 and GST-ILR1}

The amidohydrolases IAR3 and ILR1 were expressed in Escherichia Coli as a fusion to the $\mathrm{C}$ terminus of GST. pGEX-IAR3 and pGEX-ILR1 were made as reported by Davies et al. ${ }^{13}$ For protein expression, single colonies from freshly transformed BL21 (DE3) E. coli cells were inoculated into $100 \mathrm{ml}$ of Luria broth containing $100 \mu \mathrm{g} \mathrm{ml}^{-1}$ ampicillin and grown 
for $6 \mathrm{~h}$ at $37^{\circ} \mathrm{C}$. Cultures were allowed to cool to room temperature, induced by adding isopropyl-1-thio- $\beta$-D-galactopyranoside to $50 \mu \mathrm{M}$ and grown overnight with shaking at $18^{\circ} \mathrm{C}$. Cells were harvested by centrifugation and lysed by sonication, and the soluble lysate was incubated with glutathione-agarose overnight at $4{ }^{\circ} \mathrm{C}$. Fusion proteins were eluted with $5 \mathrm{mM}$ reduced glutathione in $50 \mathrm{mM}$ Tris $\left(\mathrm{pH} \mathrm{8.0)}\right.$ for $3 \mathrm{~h}$ at $4{ }^{\circ} \mathrm{C}$.

\subsubsection{Hydrolysis assays}

A hydrolysis buffer containing $50 \mathrm{mM}$ Tris- $\mathrm{HCl}(\mathrm{pH} 8.0), 1 \mathrm{mM}$ dithiothreitol, $1 \mathrm{mM}$ $\mathrm{MnCl}_{2}$, and $1 \mathrm{mM} \mathrm{ABA}$-amino acids was incubated for $5 \mathrm{~min}$ at $30^{\circ} \mathrm{C}$. Hydrolysis was

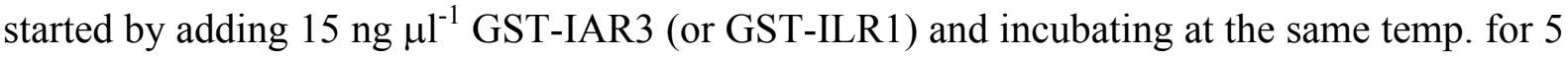
h. At each time point, $15 \mu$ of the reaction was stopped by dilution in $135 \mu$ of $\mathrm{MeOH}$ containing 1\% AcOH. Time points were taken at 2, 3, and $5 \mathrm{~h}$ for IAA-L-Ala, ABA-Gly, -L-Ala, -D-Ala, -L-Ser, -L-Thr, and -L-Asp; 2, 4, and at $7 \mathrm{~h}$ for ABA-L-Asn, -L-Gln, -L-Lys-Me, -L-His, and -L-Glu; at 2, 5, and $7 \mathrm{~h}$ for ABA-L-Val, -L-Met, -L-Pro, -L-Tyr, and -L-Cys; and at 4, 6, 24 h for ABA-L-Leu, -L-Ile, -L-Phe, and -L-Trp. The reaction mixture was loaded onto an Oasis HLB cartridge $(30 \mathrm{mg})$ and the enzyme products were eluted with $\mathrm{MeOH}$ containing $0.1 \% \mathrm{AcOH}$. After concentrating in vacuo, the dried sample was dissolved in $\mathrm{MeOH}$ (final conc. $200 \mathrm{ng} \mu \mathrm{l}^{-1}$ ) and $10 \mu \mathrm{l}$ of each sample was used in HPLC analysis: reverse phase column, YMC Hydrosphere C18 $(150 \times 6 \mathrm{~mm})$ or YMC-Pack ODS-AQ $(150 \times$

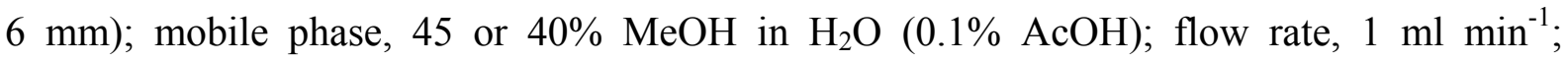
detection, $254 \mathrm{~nm}$.

\subsection{Bioassays}

\subsubsection{Arabidopsis thaliana seed germination}

Twenty-five seeds of Arabidopsis thaliana Col-0 were sterilized successively with $70 \%$ (v/v) EtOH for $30 \mathrm{~min}$ and reagent grade $\mathrm{EtOH}$ for $1 \mathrm{~min}$. The sterilized seeds were soaked in $250 \mu \mathrm{l}$ of a test solution and incubated in the dark for 3 days at $5^{\circ} \mathrm{C}$. The vernalized seeds in 
the test solution were transfered to 24-well plates in which two sheets of filter paper had been placed and allowed to germinate under continuous light for $24 \mathrm{~h}$ at $22{ }^{\circ} \mathrm{C}$. The percentage of seeds with an emerged radicle was calculated. All tests were conducted twice. The $\mathrm{IC}_{50}$ value of ABA was $0.20 \mu \mathrm{M}$.

\subsubsection{Lettuce seed germination}

Twenty-five seeds of lettuce (Lactuca sativa L. cv. Grand Rapids) were placed on two sheets of filter paper soaked in $2 \mathrm{ml}$ of a test solution in a petri dish and allowed to germinate under continuous light for $24 \mathrm{~h}$ at $22{ }^{\circ} \mathrm{C}$. The percentage of seeds with an emerged radicle was calculated. All tests were conducted twice. The $\mathrm{IC}_{50}$ value of $\mathrm{ABA}$ was $5.7 \mu \mathrm{M}$.

\subsubsection{Spinach seed germiantion}

Seeds of spinach (Spinacia oleracea L. cv. Jiromaru) were sterilized with EtOH for 5 min and washed with running tap water for $2 \mathrm{~h}$. The sterilized seeds were placed on two sheets of filter paper soaked in $2 \mathrm{ml}$ of a test solution in a petri dish and allowed to germinate under continuous light for $24 \mathrm{~h}$ at $22{ }^{\circ} \mathrm{C}$ after incubation at $5{ }^{\circ} \mathrm{C}$ for 2 days. The percentage of seeds with an emerged radicle was calculated. All tests were conducted twice. The $\mathrm{IC}_{50}$ value of ABA was $25 \mu \mathrm{M}$.

\subsubsection{Rice seedling growth}

Seeds of rice (Oryza sativa L. cv. Nipponbare) were sterilized with EtOH for 5 min and washed with running tap water. The sterilized seeds were soaked in water to germinate for 3 days at $25{ }^{\circ} \mathrm{C}$. The seeds were then placed in a glass tube containing $2 \mathrm{ml}$ of a test solution and grown with the tube sealed with a plastic cap under continuous light at $25^{\circ} \mathrm{C}$. When the seedlings were 7 days old, the length of the second leaf sheath was measured. All tests were conducted twice. The $\mathrm{IC}_{50}$ value of $\mathrm{ABA}$ was $2.1 \mu \mathrm{M}$.

\subsection{Test of ABA-L-Ala stability}


An aqueous solution $(2 \mathrm{ml})$ of ABA-L-Ala $(100 \mu \mathrm{M})$ was prepared in a glass tube as for the rice growth assay. The tube was sealed with a plastic cap and incubated under continuous light at $25^{\circ} \mathrm{C}$ for 7 days. The solution was subjected to HPLC analysis: reverse phase column, YMC-Pack ODS-AQ $(150 \times 6 \mathrm{~mm})$; mobile phase, $45 \% \mathrm{MeOH}$ in $\mathrm{H}_{2} \mathrm{O}(0.1 \% \mathrm{AcOH})$; flow

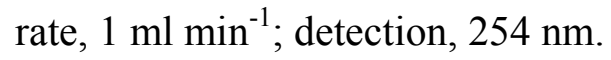

\subsection{Metabolic assay}

Forty-five germinated rice seeds were placed in a glass tube containing $2 \mathrm{ml}$ of water before incubating for 3 days. The water in the tube was removed, and $2 \mathrm{ml}$ of an aqueous solution of ABA-L-Ala- $d_{6}$ or ABA-D-Ala- $d_{6}$ was added. The seedlings were incubated for 4 days under continuous light at $25{ }^{\circ} \mathrm{C}$, and then frozen in liquid nitrogen. The frozen material was pulverized and extracted with $80 \%(\mathrm{v} / \mathrm{v})$ acetone for $24 \mathrm{~h}$ at $5{ }^{\circ} \mathrm{C}$. 1',4'-trans-diol-ABA was added as an internal standard for quantification of ABA after concentrating in vacuo. The residual solution was washed with hexane $(15 \mathrm{ml} \times 3)$ and extracted with EtOAc $(15 \mathrm{ml} \times 3)$. The combined EtOAc layer was washed with brine, dried over $\mathrm{Na}_{2} \mathrm{SO}_{4}$, and concentrated in vacuo. The residual oil was dissolved in $\mathrm{MeOH}(2 \mathrm{ml})$ before treating with TMS-diazomethane (2.0 M solution in hexane, $1 \mathrm{ml})$. The mixture was concentrated in vacuo. The residue was loaded onto Sep-Pak cartridge Plus C18 (Waters) and eluted with $\mathrm{MeOH}$ (10 $\mathrm{ml})$. The eluate was concentrated in vacuo and dissolved in $\mathrm{MeOH}(0.5 \mathrm{ml})$ for LC-MS (column, Capcell Pak C18 UG120, $150 \times 2.0$ mm I.D., Shiseido; solvent, 20-68\% MeCN in

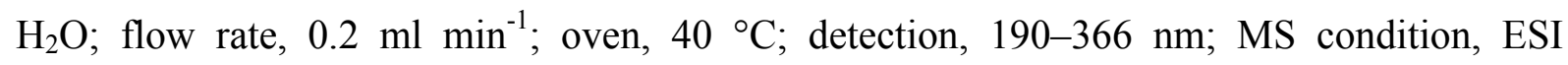
(positive), SIM mode).

\section{Acknowledgments}


We thank Toray Industries Inc., Tokyo, Japan, for the gift of (+)-ABA.

\section{Supplementary data}

Supplementary data $\left({ }^{1} \mathrm{H}\right.$ NMR spectra of new compounds) associated with this article can be found, in the online version, at doi:xx.xxxx/j.bmc.201x.xx.xxx.

\section{References and notes}

1. Hirai, N. In Comprehensive Natural Products Chemistry; Mori, K., Ed.; Elsevier: Amsterdam, 1999; Vol. 8, pp. 72-91.

2. Zeevaart, J. A. D.; Creelman, R. A. Annu. Rev. Plant Physiol. Plant Mol. Biol. 1988, 39, 439.

3. Nambara, E.; Marion-Poll, A. Annu. Rev. Plant Biol. 2005, 56, 165.

4. Saito, S.; Hirai, N.; Matsumoto, C.; Ohigashi, H.; Ohta, D.; Sakata, K.; Mizutani, M. Plant Physiol. 2004, 134, 1439.

5. Kushiro, T.; Okamoto, M.; Nakabayashi, K.; Yamagishi, K.; Kitamura, S.; Asami, T.; Hirai,N.; Koshiba, T.; Kamiya, Y.; Nambara, E. ENBO J. 2004, 23, 1647.

6. Loveys, B. R.; Milborrow, B. V. In The biosynthesis and metabolism of plant hormones; Crozier, A.; Hillman, J. R., Eds.; Cambridge University Press, London, 1984, pp. 71-104.

7. Cohen, J. D.; Bandurski, R. S. Annu. Rev. Plant Physiol. 1982, 33, 403.

8. Sembdner, G.; Parthier, B. Annu. Rev. Plant Physiol. Plant Mol. Biol. 1993, 44, 569.

9. Lee, H.-I.; León, J.; Raskin, I. Proc. Natl. Acad. Sci. USA, 1995, 92, 4076. 
10. Fonseca, S.; Chini, A.; Hamberg, M.; Adie, B.; Porzel, A.; Kramell, R.; Miersch, O.; Wasternack, C.; Solano, R. Nature Chem. Biol. 2009, 5, 344.

11. Biraboneye, A. C.; Madonna, S.; Laras, Y.; Krantic, S.; Maher, P.; Kraus, J.-L. J. Med. Chem. 2009, 52, 4358.

12. Bartel, B.; Fink, G. R. Science 1995, 268, 1745.

13. Davies, R. T.; Goetz, D. H.; Lasswell, J.; Anderson, M. N.; Bartel, B. Plant Cell 1999, 11, 365.

14. LeClere, S.; Tellez, R.; Rampey, R. A.; Matsuda, S. P. T.; Bartel, B. J. Biol. Chem. 2002, $277,20446$.

15. Campanella, J. J.; Olajide, A. F.; Magnus, V.; Ludwig-Müller, J. Plant Physiol. 2004, 135, 2230.

16. Rampey, R. A.; LeClere, S.; Kowalczyk, M.; Ljung, K.; Sandberg, G.; Bartel, B. Plant Physiol. 2004, 135, 978.

17. Schuller, A.; Ludwig-Müller, J. New Phytol. 2006, 171, 145.

18. Todoroki, Y.; Hirai, N. In Studies in Natural Products Chemistry; Atta-ur-Rahman, Ed.; Elsevier Science B. V.: Amsterdam, 2002; Vol. 27, pp. 321-360.

19. Nishimura, N.; Hitomi, K.; Arvai, A. S.; Rambo, R. P.; Hitomi, C.; Cutler, S. R.; Schroeder, J. I.; Getzoff, E. D. Science 2009, 326, 1373.

20. Melcher, K.; Ng, L.-M.; Zhou, X. E.; Soon, F.-F.; Xu, Y.; Suino-Powell, K. M.; Park, S.-Y.; Weiner, J., J.; Fujii, H.; Chinnusamy, V.; Kovach, A.; Li, J.; Wang, Y.; Li, J.; Peterson, F. C.; Jensen, D. R.; Yong, E.-Y.; Volkman, B. F.; Cutler, S. R.; Zhu, J.-K.; Xu, H. E. Nature 2009, 462, 602. 
21. Santiago, J.; Dupeux, F.; Round, A.; Antoni, R.; Park, S.-Y.; Jamin, M.; Cutler, S. R.; Rodriguez, P. L.; Ma'rquez, J. A. Nature 2009, 462, 665.

22. Miyazono, K.; Miyakawa, T.; Sawano, Y.; Kubota, K.; Kang, H.-J.; Asano, A.; Miyauchi, Y.; Takahashi, M.; Zhi, Y.; Fujita, Y.; Yoshida, T.; Kodaira, K.; Yamaguchi-Shinozaki, K.; Tanokura, M. Nature 2009, 462, 609.

23. Yin, P.; Fan, H.; Hao, Q.; Yuan, X.; Wu, D.; Pang, Y.; Yan, C.; Li, W.; Wang, J.; Yan, N. Nat. Struct. Mol. Biol. 2009, 16, 1230.

24. Campanella, J. J.; Larko, D.; Smalley, J. Comp. Funct. Genom. 2003, 4, 584. 
Table and Figure legends

\section{Table 1}

Exact mass data (ESI-TOF, positive/negative) and reverse-phase HPLC-based purity of ABA-amino acids

\section{Table 2}

$\mathrm{IC}_{50}$ values of $\mathrm{ABA}$ and $\mathrm{ABA}$-amino acids in a rice elongation assay

\section{Table 3}

Amidohydrolase activity of Arabidopsis GST-IAR3 in releasing ABA from ABA-amino acids

Figure 1. The major catabolic pathway of ABA in plants. Endogenous ABA-amino acid conjugates have not been identified.

Figure 2. Preparation of ABA-amino acids. Reagents and conditions: (i) $\mathrm{PCl}_{3}$ in $\mathrm{CH}_{2} \mathrm{Cl}_{2}$, room temp., $1 \mathrm{~h}$; (ii) room temp. $1 \mathrm{~h}$; (iii) $0.5-1 \mathrm{M} \mathrm{NaOH}$ in $\mathrm{MeOH}$ or formic acid, room temp., $1-3 \mathrm{~h}$.

Figure 3. Inhibitory activity of ABA-amino acid conjugates in four bioassays. The conjugate is showed by the one-letter amino acid symbol. ABA-L-Lys was the methyl ester. (a) Arabidopsis seed germination. (b) Lettuce seed germination. (c) Spinach seed germination. (d) Rice seedling elongation. ABA exhibited 100\% inhibition in all the assays, whereas ABA-methylamide and free amino acids showed no inhibition (data not shown).

Figure 4. Stability of ABA-L-Ala in aqueous solution under the same conditions as those in 
the rice seedling elongation assay $\left(25^{\circ} \mathrm{C}\right.$, continuous light, 7-day incubation period). HPLC chromatograms: (a) ABA-L-Ala solution at day 0; (b) ABA-L-Ala solution at day 7; and (c) ABA standard solution.

Figure 5. Mass chromatograms at $m / z 267\left[\mathrm{M}-\mathrm{H}_{2} \mathrm{O}+\mathrm{H}\right]^{+}$in an LC-MS analysis of methylated $80 \%$ acetone extract of rice seedlings fed ABA-L-Ala or ABA-D-Ala. (a) Methyl ABA- $d_{6}$ standard sample. (b) Unfed control sample. (c) Sample fed ABA-L-Ala. (d) Sample fed ABA-D-Ala. 


\section{Table 1}

Exact mass data (ESI-TOF, positive/negative) and reverse-phase HPLC-based purity of ABA-amino acids

\begin{tabular}{|c|c|c|c|c|c|}
\hline \multirow{2}{*}{ Compound } & \multicolumn{2}{|c|}{$[\mathrm{M}+\mathrm{Na}]^{+} /[\mathrm{M}+\mathrm{H}]^{+} /[\mathrm{M}-\mathrm{H}]^{-}$} & \multirow{2}{*}{$\begin{array}{c}\Delta \\
(\mathrm{mmu})\end{array}$} & \multirow{2}{*}{ Elemental composition } & \multirow{2}{*}{$\begin{array}{c}\text { HPLC-based } \\
\text { ABA contaminant }(\%)\end{array}$} \\
\hline & Theoretical & Experimental & & & \\
\hline ABA-Gly & 344.1474 & 344.1474 & 0 & $\mathrm{C}_{17} \mathrm{H}_{23} \mathrm{NNaO}_{5}^{+}$ & $\mathrm{nd}^{\mathrm{b}}$ \\
\hline -L-Ala & 358.1630 & 358.1626 & -0.4 & $\mathrm{C}_{18} \mathrm{H}_{25} \mathrm{NNaO}_{6}^{+}$ & nd \\
\hline -D-Ala & 358.1630 & 358.1637 & 0.7 & $\mathrm{C}_{18} \mathrm{H}_{25} \mathrm{NNaO}_{6}^{+}$ & nd \\
\hline$-\mathrm{L}-\mathrm{Val}$ & 386.1943 & 386.1937 & -0.6 & $\mathrm{C}_{20} \mathrm{H}_{29} \mathrm{NNaO}_{5}^{+}$ & 0.10 \\
\hline -L-Leu & 400.2100 & 400.2099 & -0.1 & $\mathrm{C}_{21} \mathrm{H}_{31} \mathrm{NNaO}_{5}^{+}$ & nd \\
\hline -L-Ile & 400.2100 & 400.2100 & 0 & $\mathrm{C}_{21} \mathrm{H}_{31} \mathrm{NNaO}_{5}^{+}$ & nd \\
\hline -L-Met & 394.1688 & 394.1689 & 0.1 & $\mathrm{C}_{20} \mathrm{H}_{28} \mathrm{NO}_{5} \mathrm{~S}^{+}$ & nd \\
\hline -L-Pro & 384.1787 & 384.1784 & -0.3 & $\mathrm{C}_{20} \mathrm{H}_{27} \mathrm{NNaO}_{5}^{+}$ & nd \\
\hline -L-Phe & 434.1943 & 434.1947 & 0.4 & $\mathrm{C}_{24} \mathrm{H}_{29} \mathrm{NNaO}_{5}^{+}$ & nd \\
\hline$-\mathrm{L}-\mathrm{Trp}$ & 473.2052 & 473.2051 & -0.1 & $\mathrm{C}_{26} \mathrm{H}_{30} \mathrm{~N}_{2} \mathrm{NaO}_{5}^{+}$ & nd \\
\hline -L-Ser & 374.1580 & 374.1577 & -0.3 & $\mathrm{C}_{18} \mathrm{H}_{25} \mathrm{NNaO}_{6}^{+}$ & nd \\
\hline -L-Thr & 364.1760 & 364.1759 & -0.1 & $\mathrm{C}_{19} \mathrm{H}_{26} \mathrm{NO}_{6}^{-}$ & nd \\
\hline -L-Asn & 401.1689 & 401.1687 & -0.2 & $\mathrm{C}_{19} \mathrm{H}_{26} \mathrm{~N}_{2} \mathrm{NaO}_{6}^{+}$ & nd \\
\hline -L-Gln & 415.1845 & 415.1848 & 0.3 & $\mathrm{C}_{20} \mathrm{H}_{28} \mathrm{NNaO}_{6}^{+}$ & nd \\
\hline -L-Tyr & 450.1893 & 450.1892 & -0.1 & $\mathrm{C}_{24} \mathrm{H}_{29} \mathrm{NNaO}_{6}^{+}$ & nd \\
\hline -L-Cys & 366.1375 & 366.1371 & -0.4 & $\mathrm{C}_{24} \mathrm{H}_{29} \mathrm{NNaO}_{6}^{-}$ & nd \\
\hline -L-Lys ${ }^{\mathrm{a}}$ & 407.2546 & 407.2547 & 0.1 & $\mathrm{C}_{22} \mathrm{H}_{34} \mathrm{~N}_{2} \mathrm{O}_{5}^{+}$ & nd \\
\hline -L-His & 424.1848 & 424.1846 & -0.2 & $\mathrm{C}_{21} \mathrm{H}_{27} \mathrm{~N}_{3} \mathrm{NaO}_{5}^{+}$ & nd \\
\hline -L-Asp & 378.1553 & 378.1552 & -0.1 & $\mathrm{C}_{19} \mathrm{H}_{24} \mathrm{NO}_{7}^{-}$ & nd \\
\hline -L-Glu & 416.1685 & 416.1684 & -0.1 & $\mathrm{C}_{20} \mathrm{H}_{27} \mathrm{NNaO}_{7}^{+}$ & nd \\
\hline
\end{tabular}

${ }^{a}$ The methyl ester.

${ }^{\mathrm{b}}$ Not detected. 
Table 2

The $\mathrm{IC}_{50}$ values of $\mathrm{ABA}$ and $\mathrm{ABA}$-amino acids in the rice elongation assay

\begin{tabular}{rc}
\hline Compound & $\mathrm{IC}_{50}(\mu \mathrm{M})$ \\
\hline ABA-Gly & 5.7 \\
-L-Ala & 7.0 \\
-L-Met & 16 \\
-L-Ser & 13 \\
-L-Asn & 9.3 \\
-L-Gln & 8.3 \\
-L-Asp & 6.4 \\
\hline ABA & 2.1 \\
\hline
\end{tabular}




\section{Table 3}

Amidohydrolase activity of Arabidopsis GST-IAR3

to release ABA from ABA-amino acids

\begin{tabular}{|c|c|}
\hline Substrate & $\mathrm{nmol} \mathrm{ABA}$ released $/ \mathrm{h} / \mathrm{mg}^{\mathrm{b}}$ \\
\hline ABA-Gly & 230 \\
\hline -L-Ala & 310 \\
\hline -D-Ala & nd \\
\hline -L-Val & nd \\
\hline -L-Leu & nd \\
\hline -L-Ile & nd \\
\hline -L-Met & 22 \\
\hline -L-Pro & nd \\
\hline -L-Phe & nd \\
\hline -L-Trp & nd \\
\hline -L-Ser & nd \\
\hline -L-Thr & nd \\
\hline -L-Asn & 19 \\
\hline -L-Gln & nd \\
\hline -L-Tyr & nd \\
\hline -L-Cys & nd \\
\hline- L-Lys $^{\mathrm{a}}$ & nd \\
\hline -L-His & nd \\
\hline -L-Asp & nd \\
\hline -L-Glu & nd \\
\hline IAA-L-Ala & $\begin{array}{c}2100 \\
(\mathrm{nmol} \text { IAA released } / \mathrm{h} / \mathrm{mg})\end{array}$ \\
\hline
\end{tabular}

${ }^{a}$ The methyl ester.

${ }^{\mathrm{b}}$ Mean values of two independent experiments are given. 


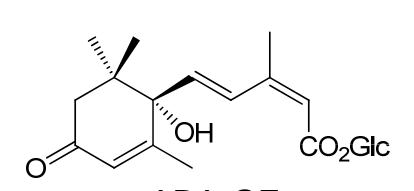

ABA-GE

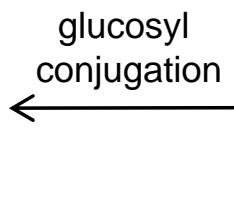

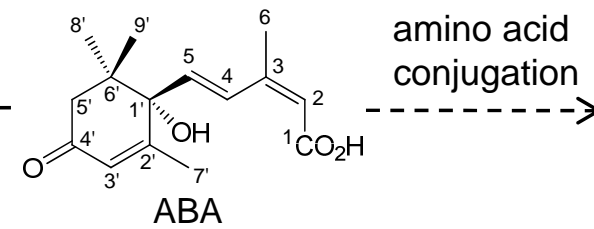

hydroxylation

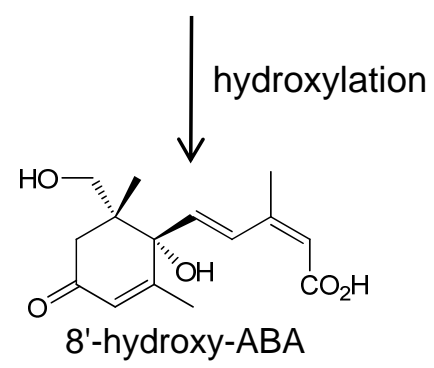<smiles>[R]C(NC(=O)C=C(C)C=CC1(C)C(C(C)(C)C)=CC(=O)CC1(C)C)C(=O)O</smiles>

Fig. 1 
(+)-ABA

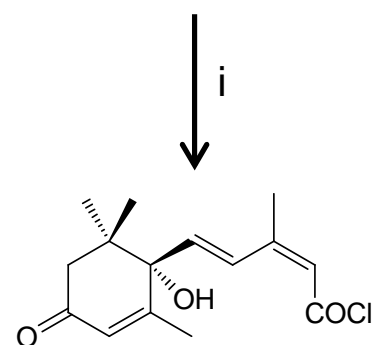

1<smiles>[R]OC(=[R])C([R])N</smiles>

amino acid ester

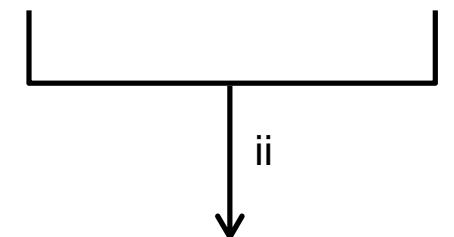<smiles>[R]C(=O)C([R1])NC(=O)/C=C(C)\C=C\C1(O)C(C)=CC(=O)CC1(C)C</smiles>

ABA-amino acid ester<smiles>[R]C(NC(=O)/C=C(C)\C=C\C1(O)C(C)=CC(=O)CC1(C)C)C(=O)OC(=O)O</smiles>

ABA-amino acid

Fig. 2 

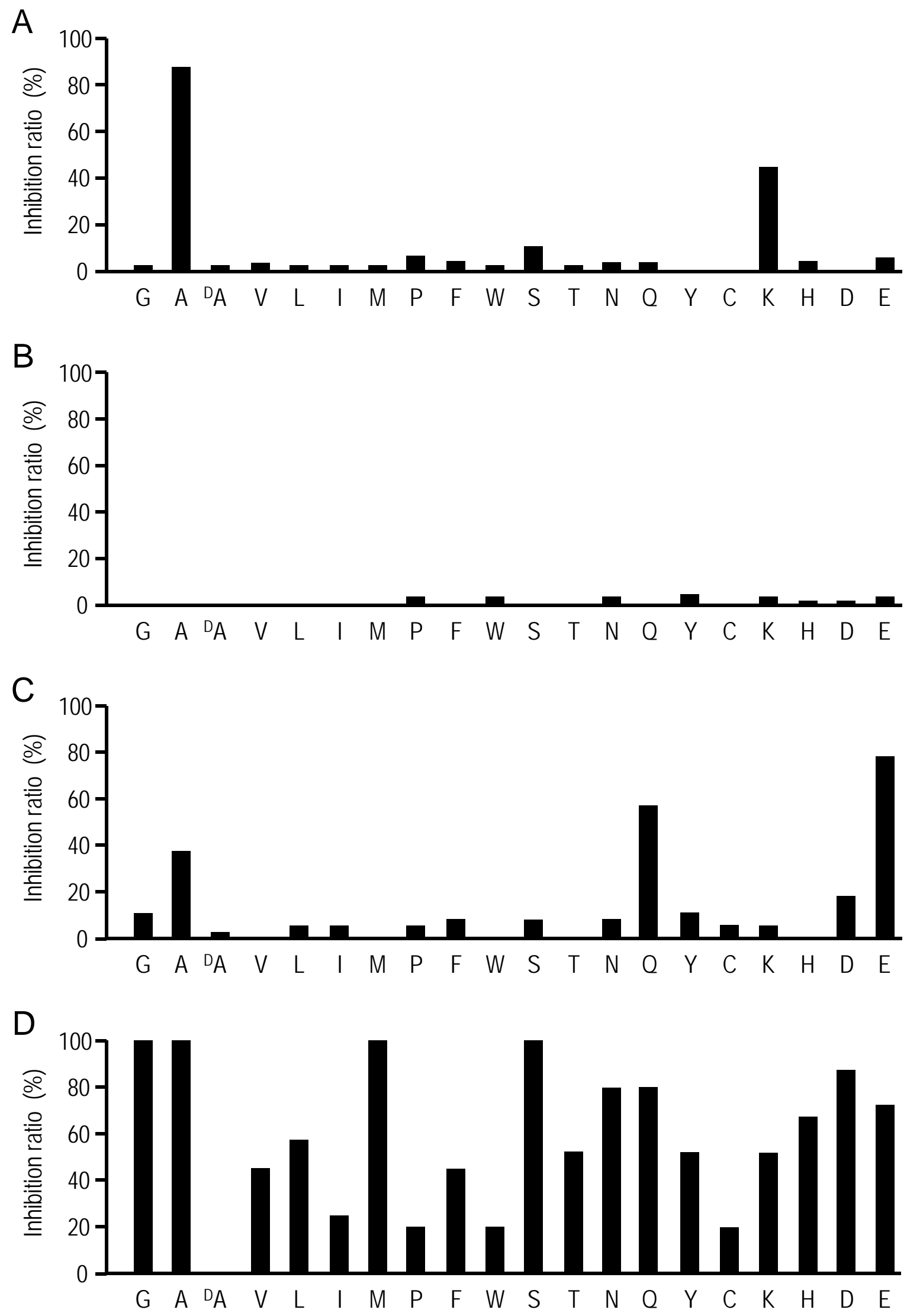

Fig. 3 

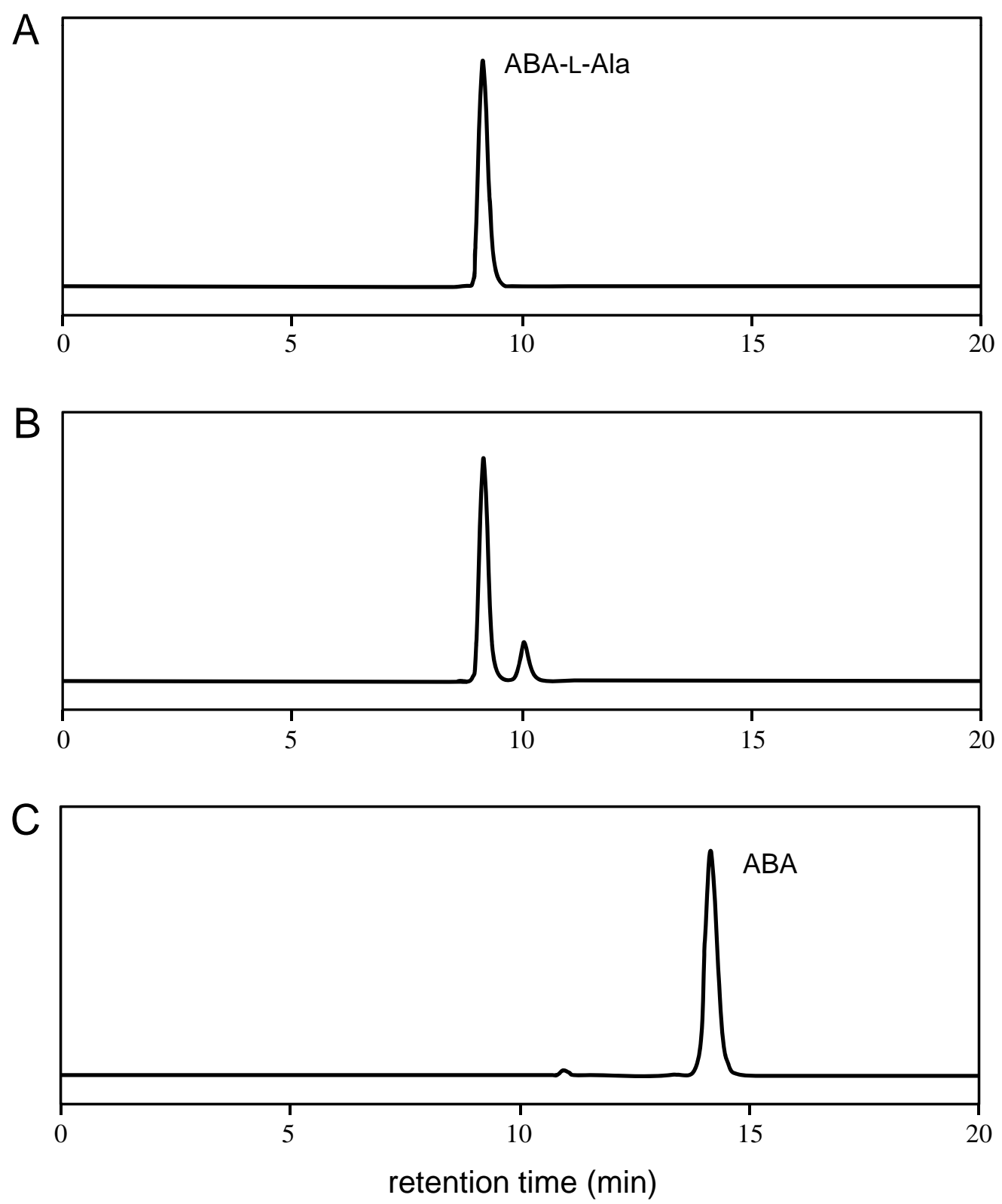

Fig. 4 


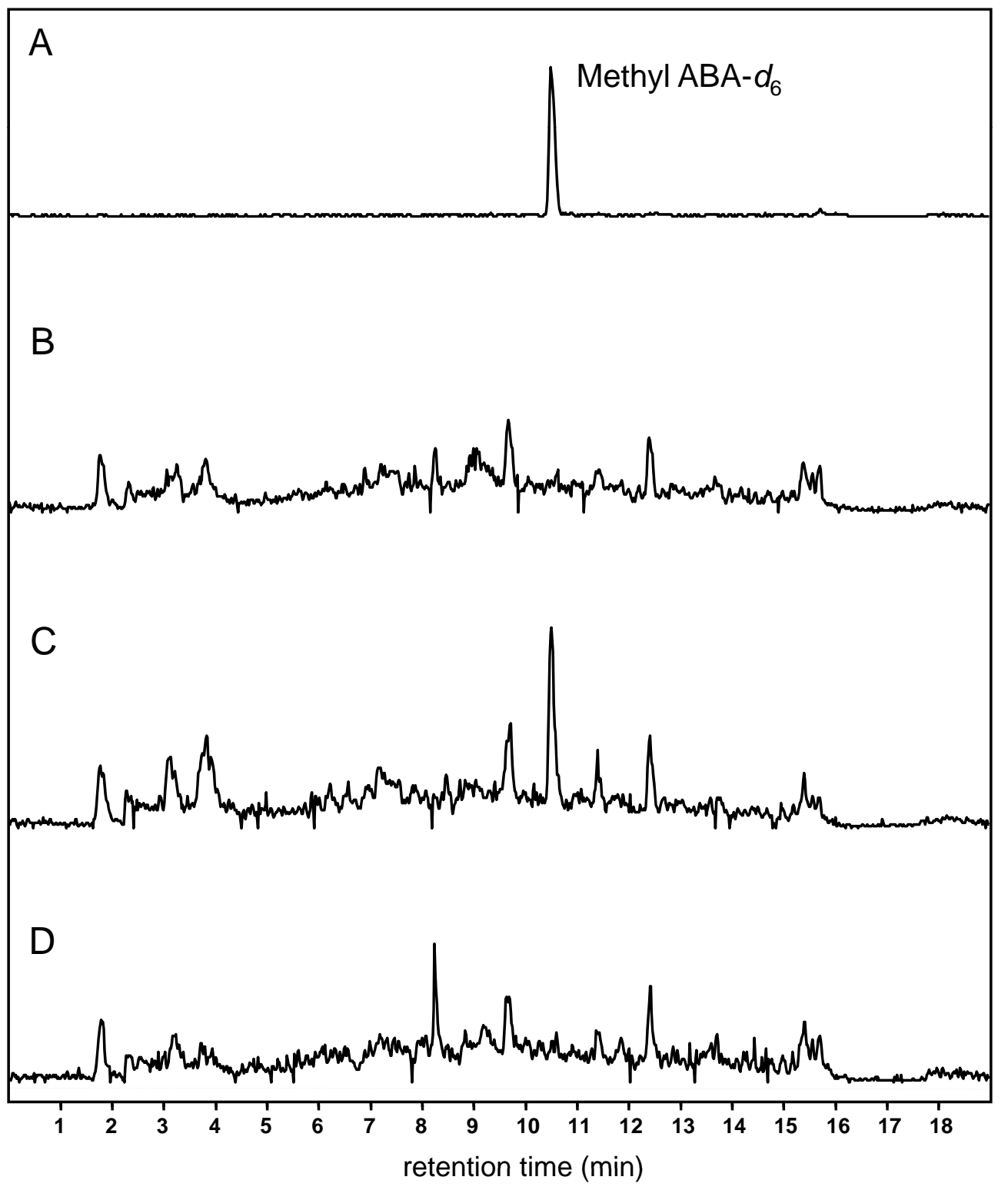

Fig. 5 


\title{
Synthesis and biological activity of amino acid conjugates of abscisic acid
}

\author{
Yasushi Todoroki ${ }^{\mathrm{a}, *}$, Kenta Narita ${ }^{\mathrm{a}}$, Taku Muramatsu ${ }^{\mathrm{a}}$, Hajime Shimomura ${ }^{\mathrm{a}}$, Toshiyuki Ohnishi ${ }^{\mathrm{b}}$, \\ Masaharu Mizutani $^{\mathrm{c},}$, Kotomi Ueno ${ }^{\mathrm{a}, \dagger}$, Nobuhiro Hirai ${ }^{\mathrm{d}}$
}

\section{Supplementary data}

${ }^{1} \mathrm{H}$ NMR spectra of new compounds 


\section{ABA-Gly}

141-93-2 (ABA-Gly)

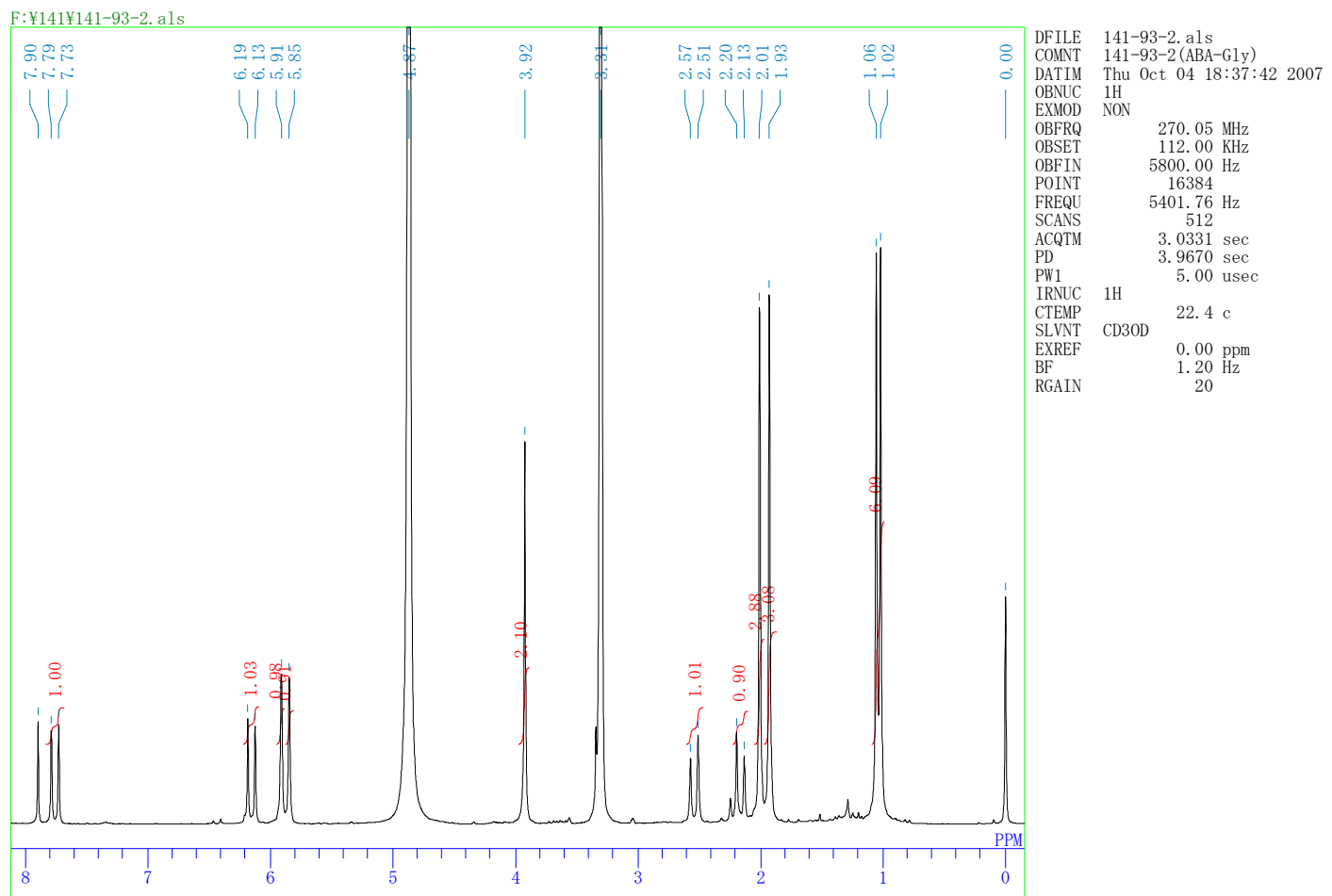

ABA-L-Ala

190-87-3

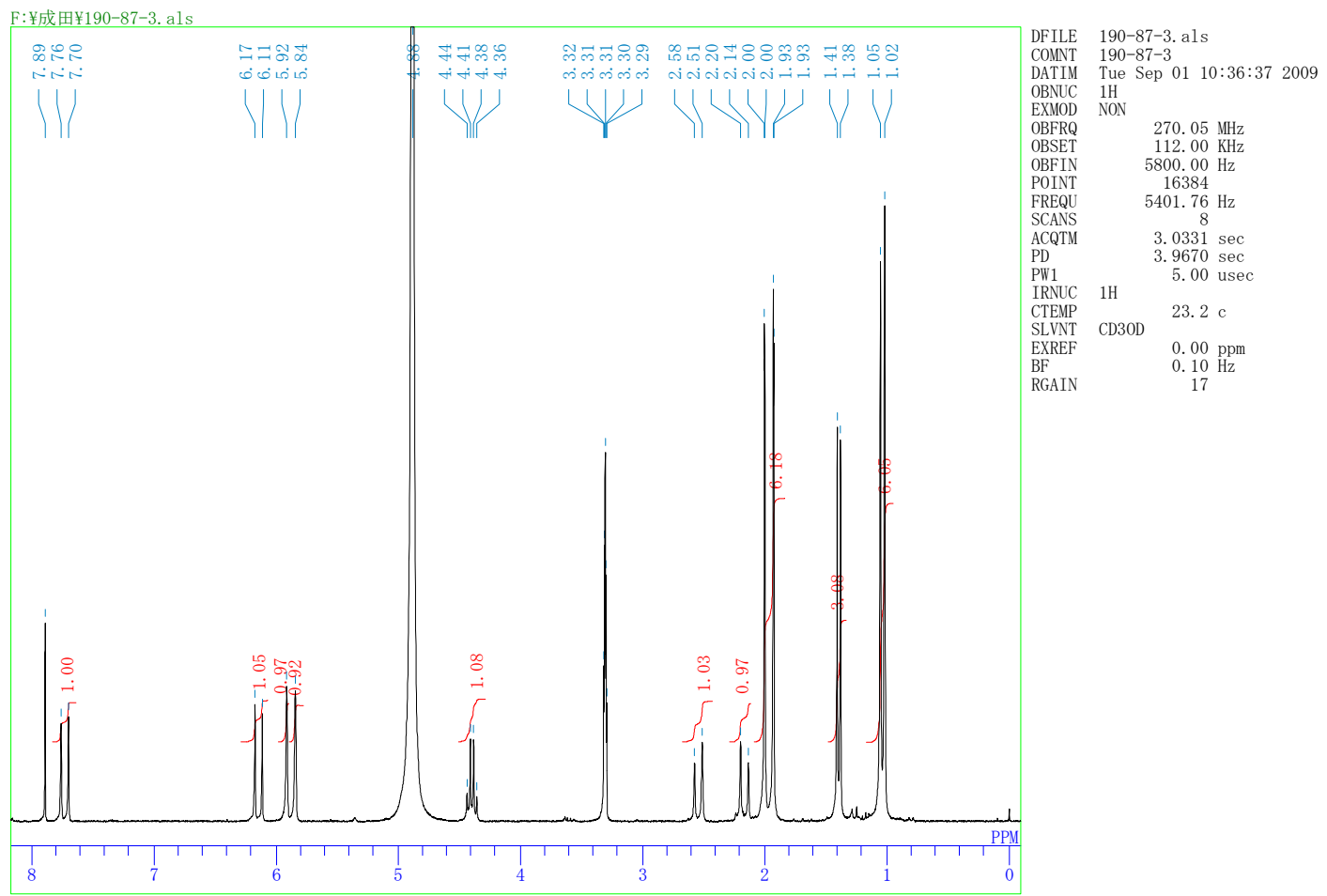


ABA-D-Ala

196-13-2

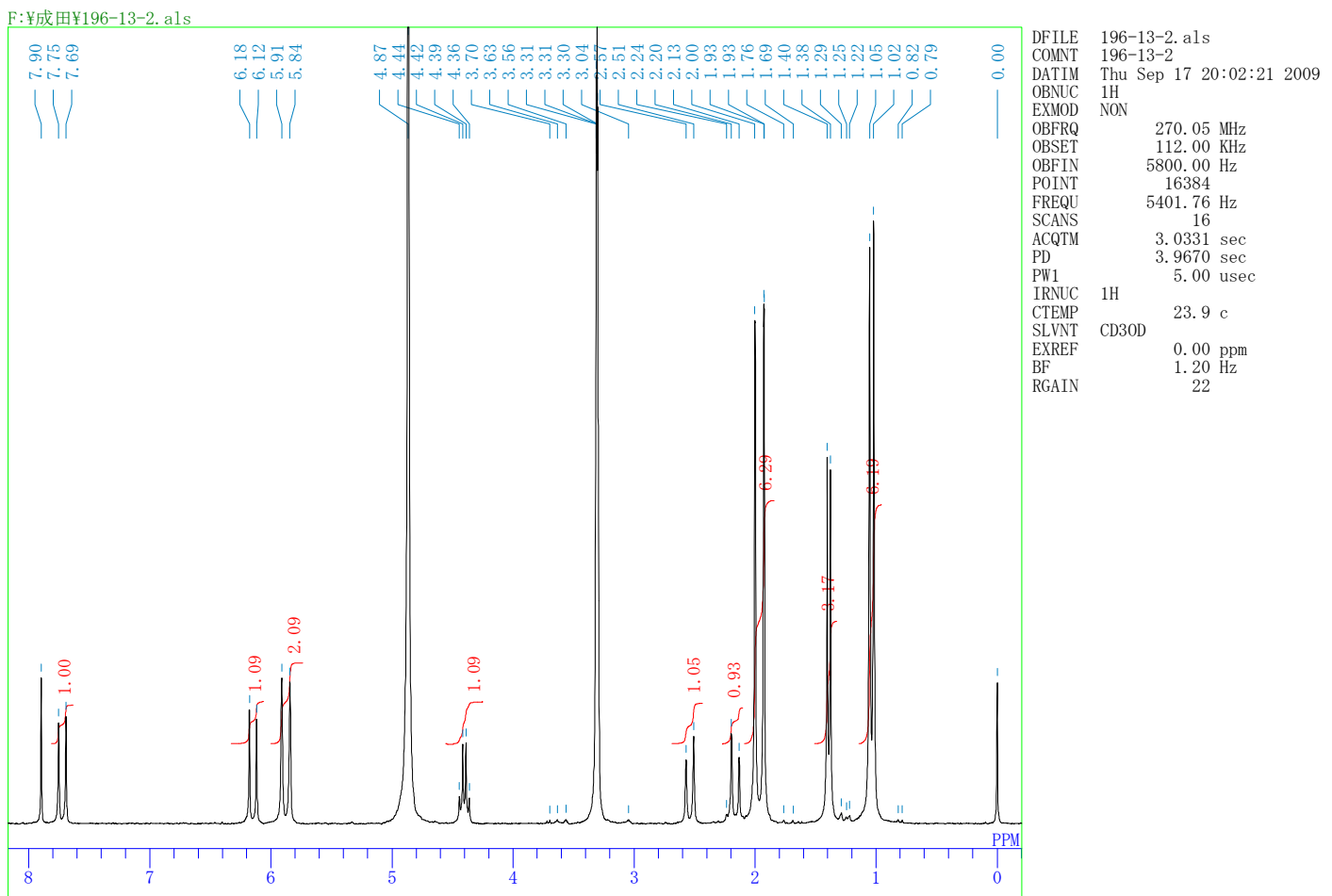

ABA-Val

134-45-3 (ABA-Val)

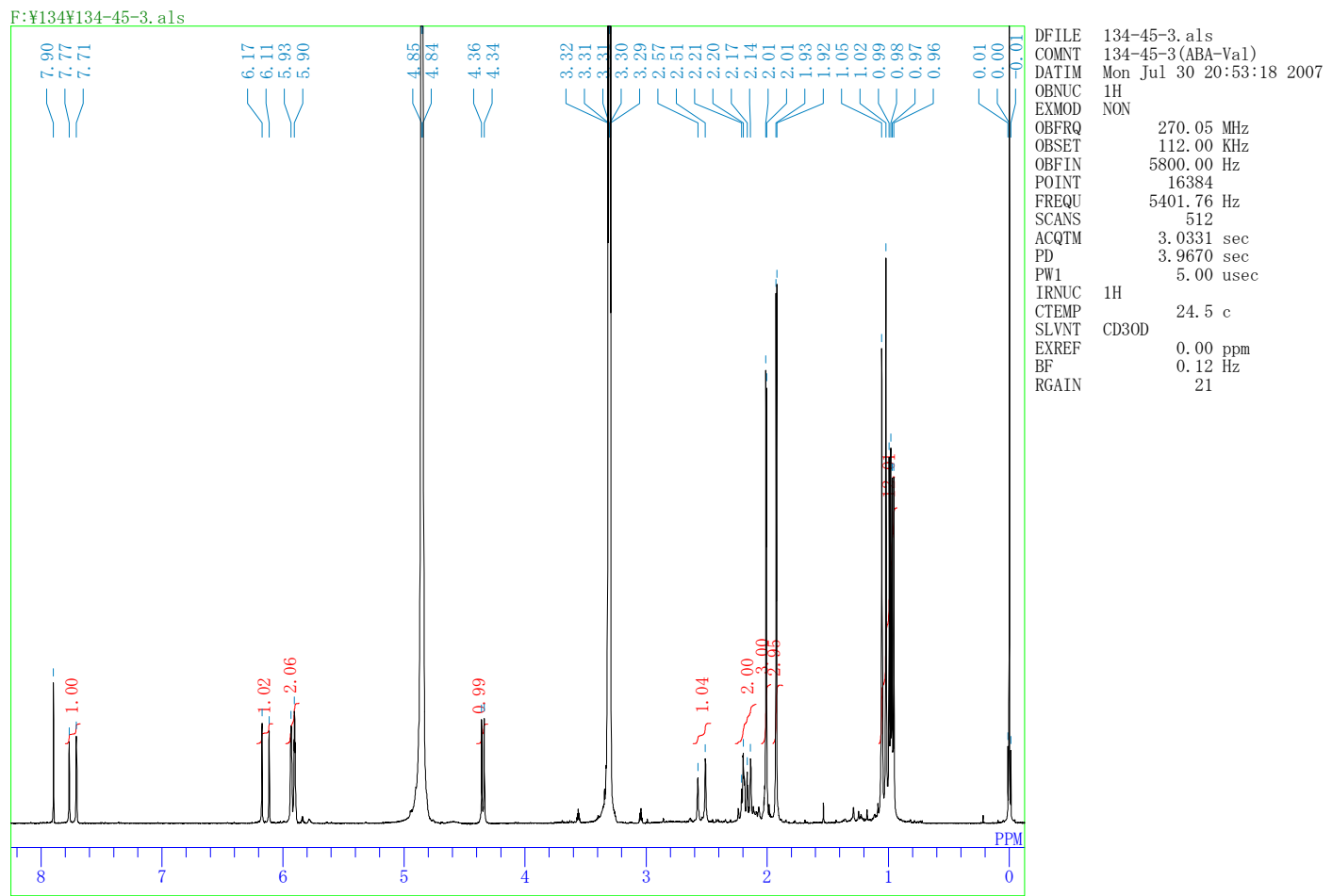


ABA-Leu

134-15-1

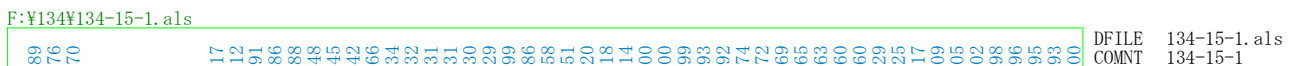

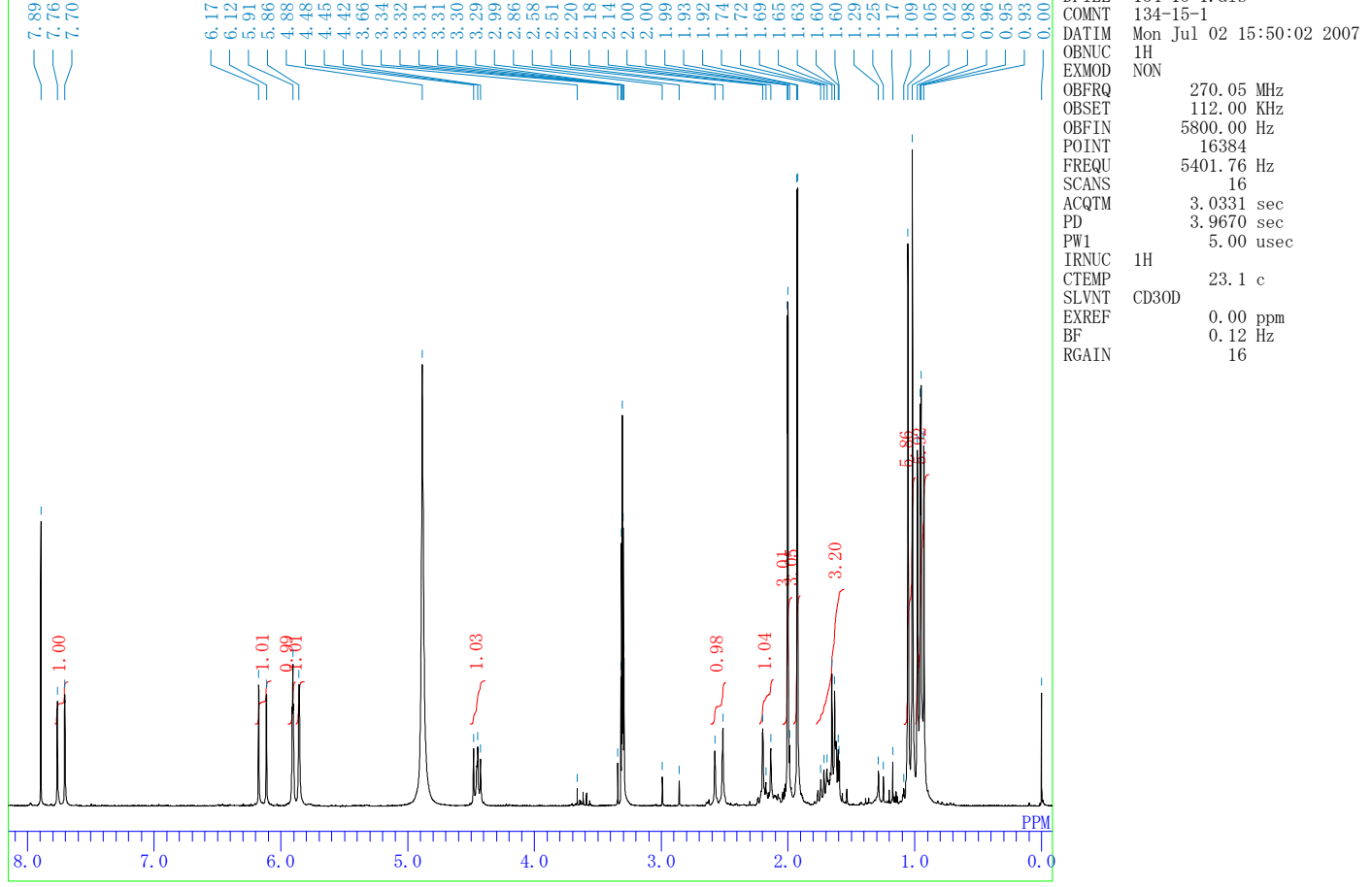

ABA-Ile

134-73-1 (ABA-Ile)

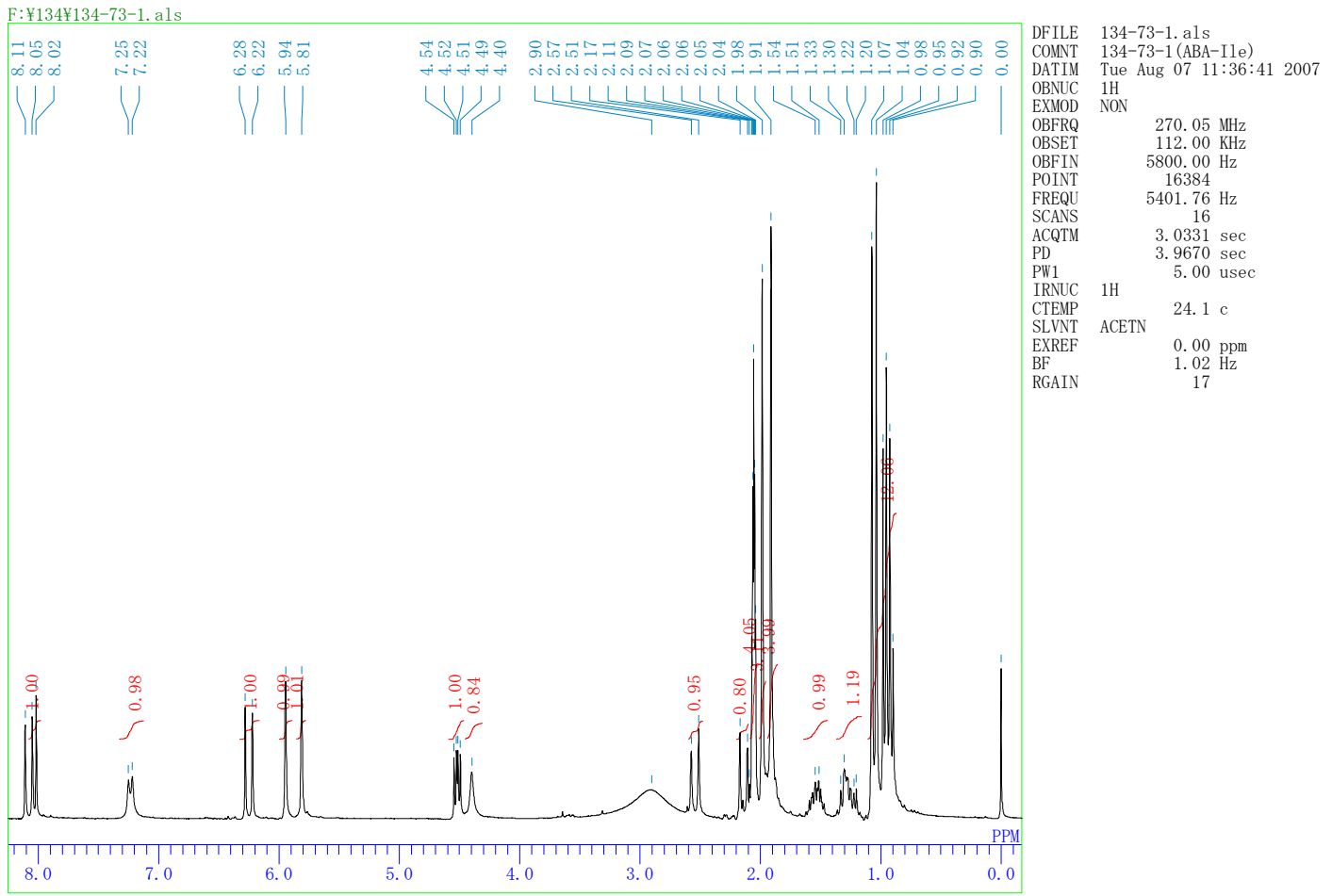




\section{ABA-Met}

ABA-Met

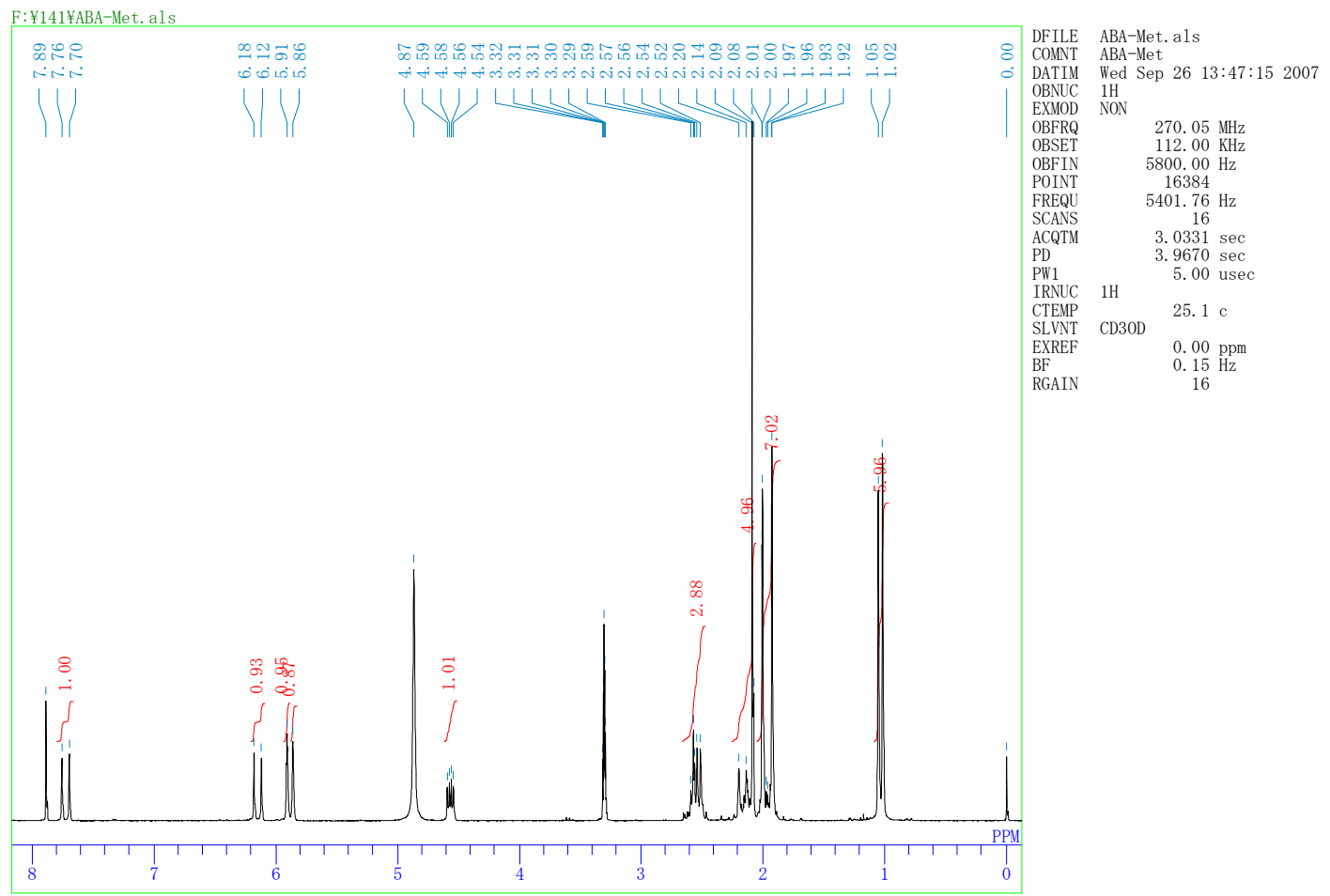

ABA-Pro

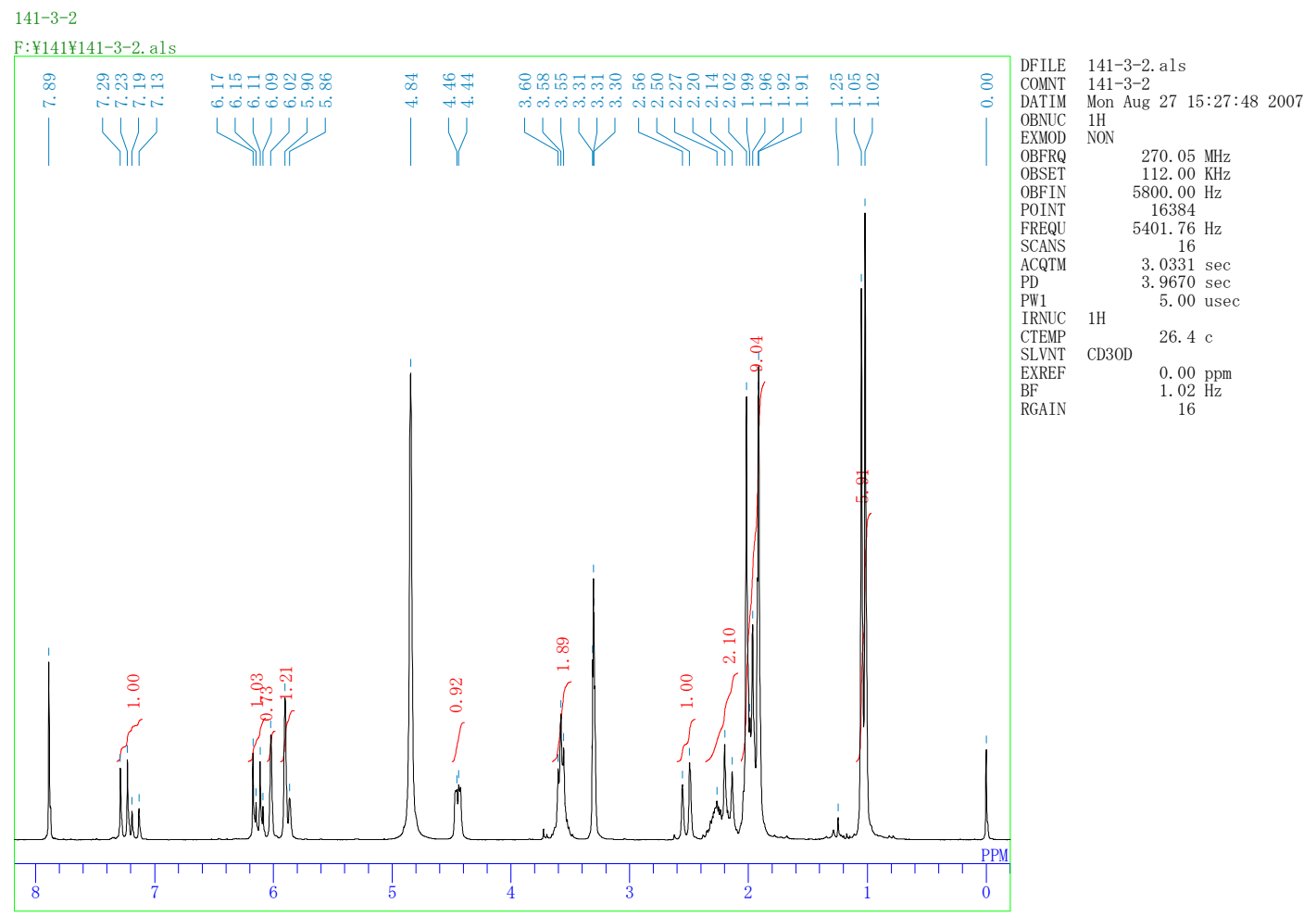




\section{ABA-Phe}

120-93-2

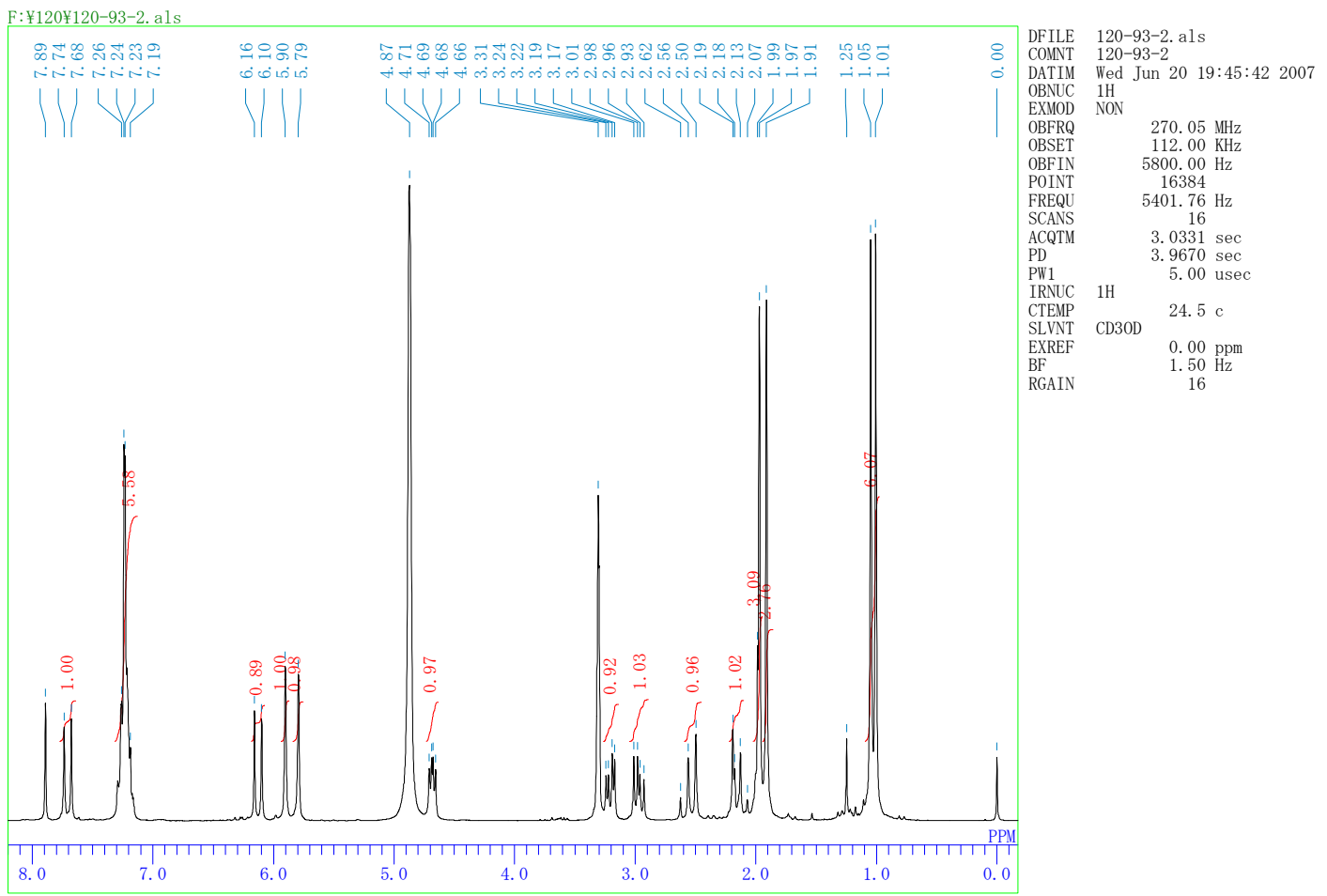

ABA-Trp

134-93-1 (ABA-Trp)

F:¥134¥134-93-1.als

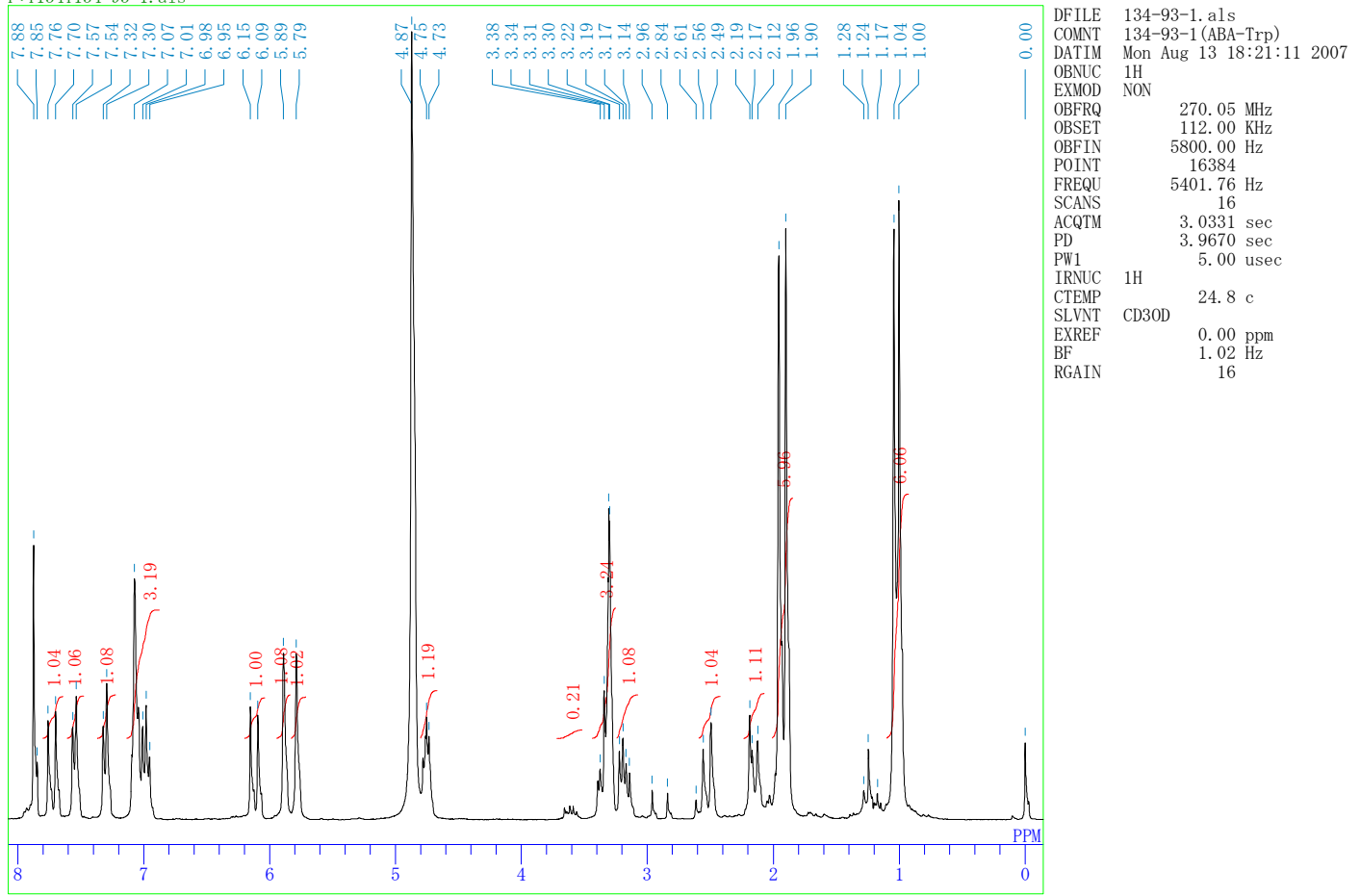




\section{ABA-Ser}

134-55-2

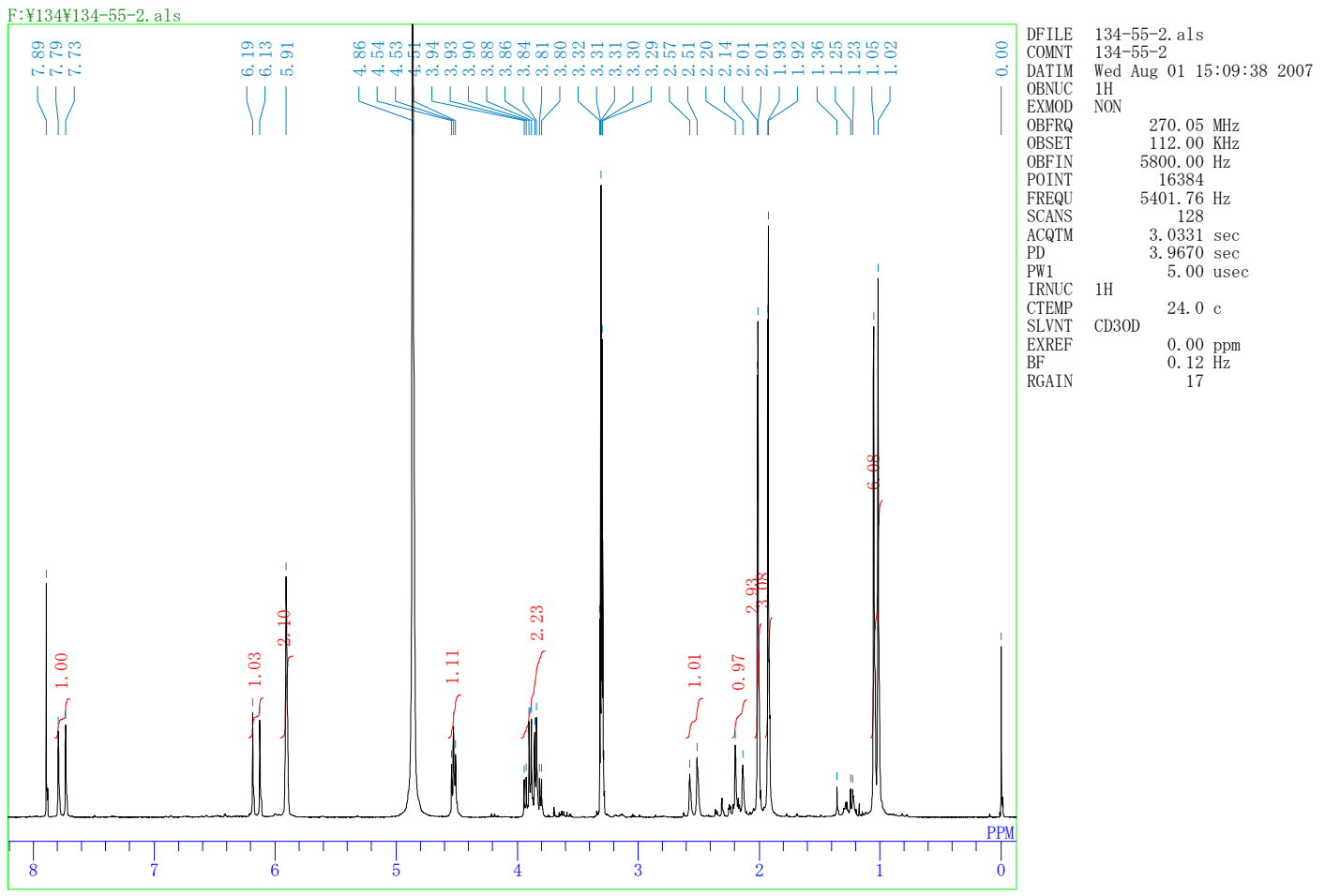

ABA-Thr

ABA-Thr

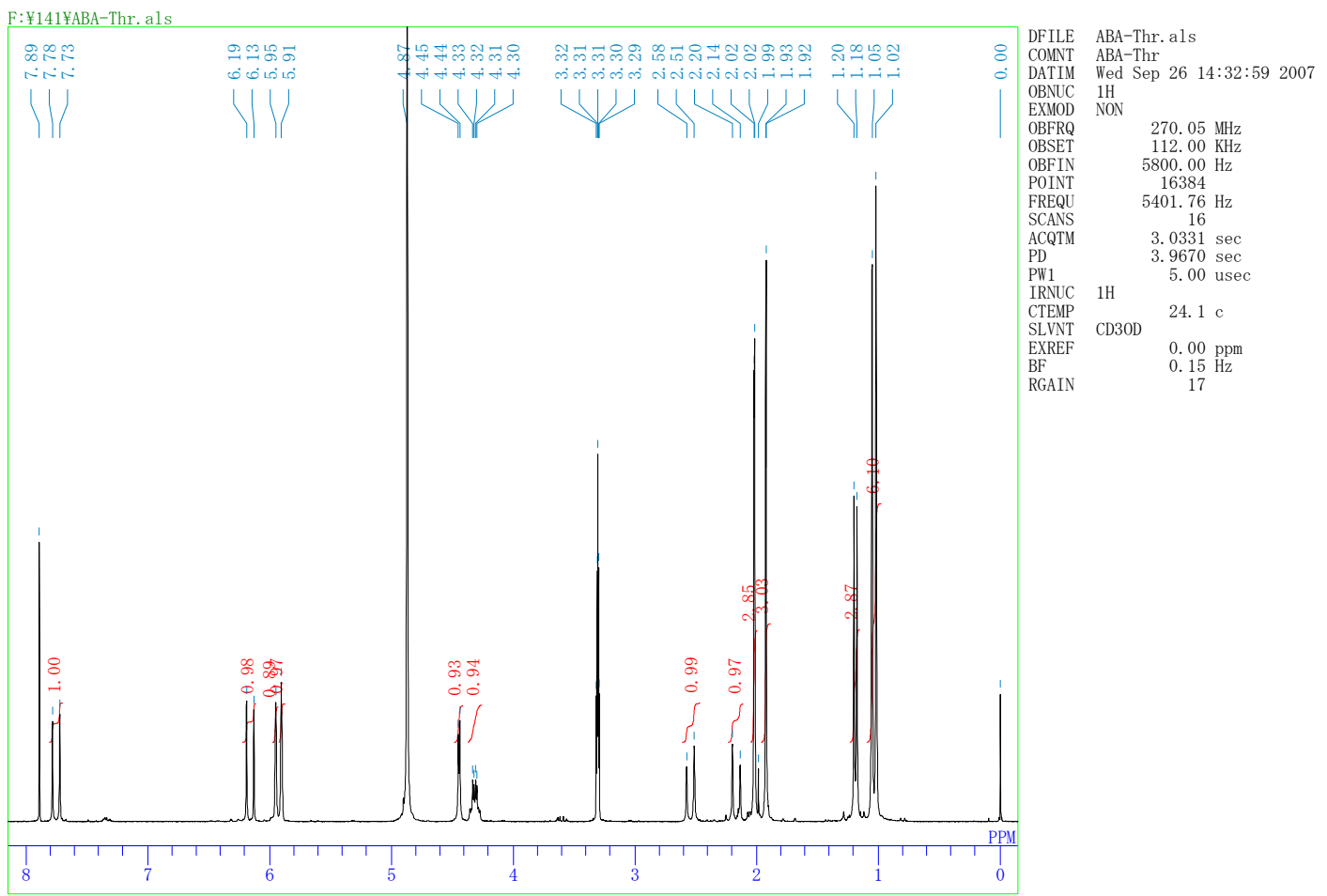


ABA-Asn

148-61-2 (ABA-Asn)

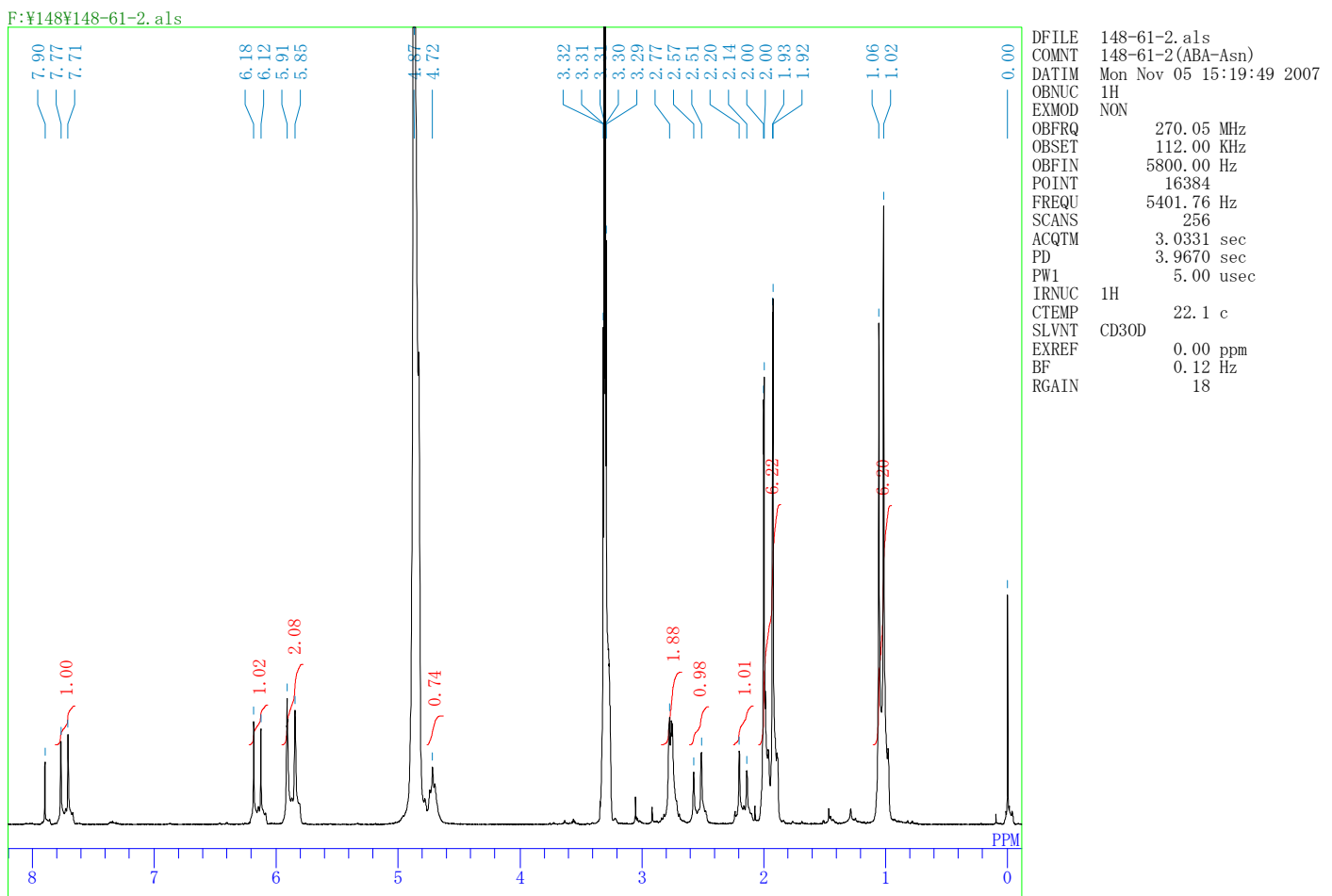

ABA-Gln

161-19-3

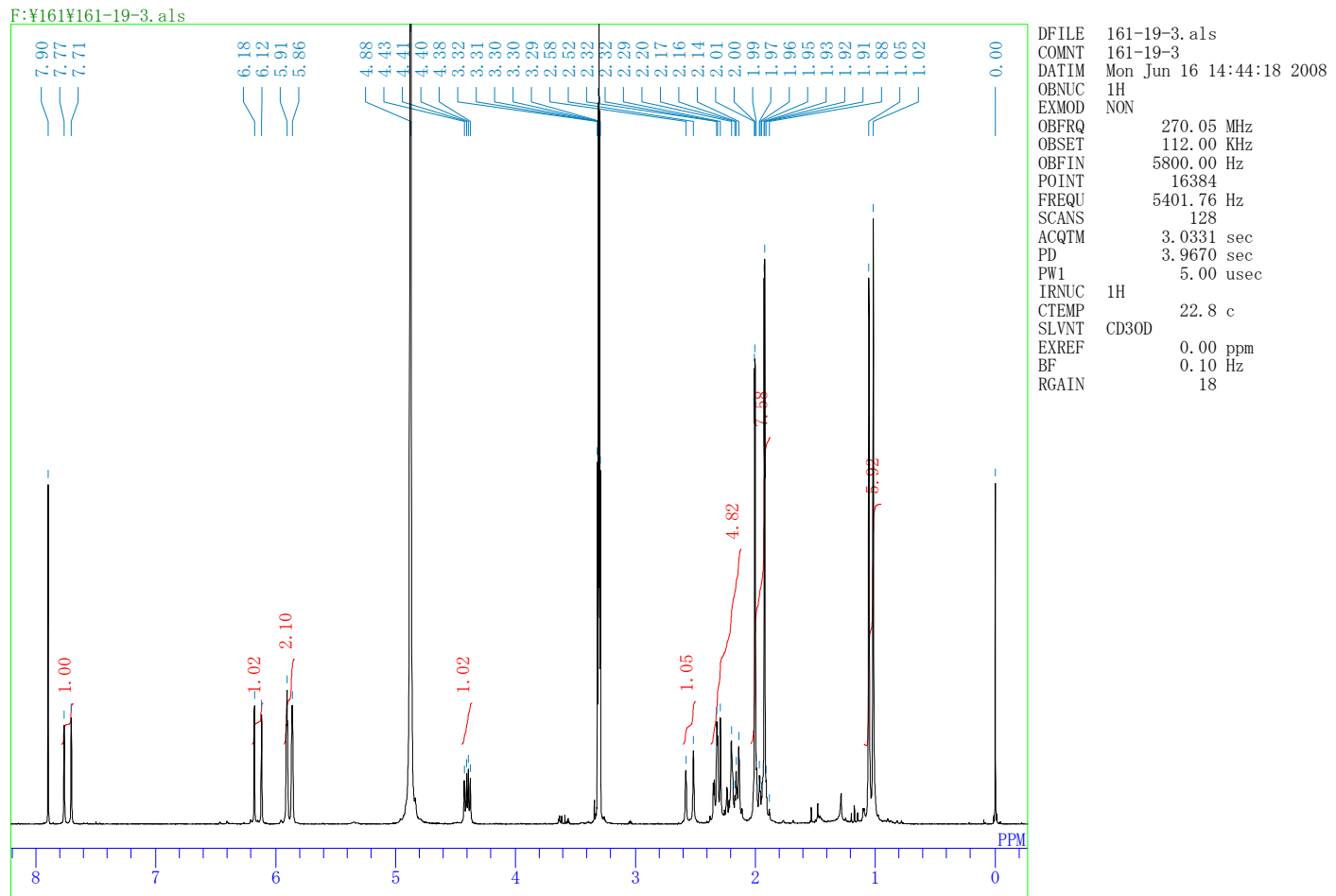




\section{ABA-Tyr}

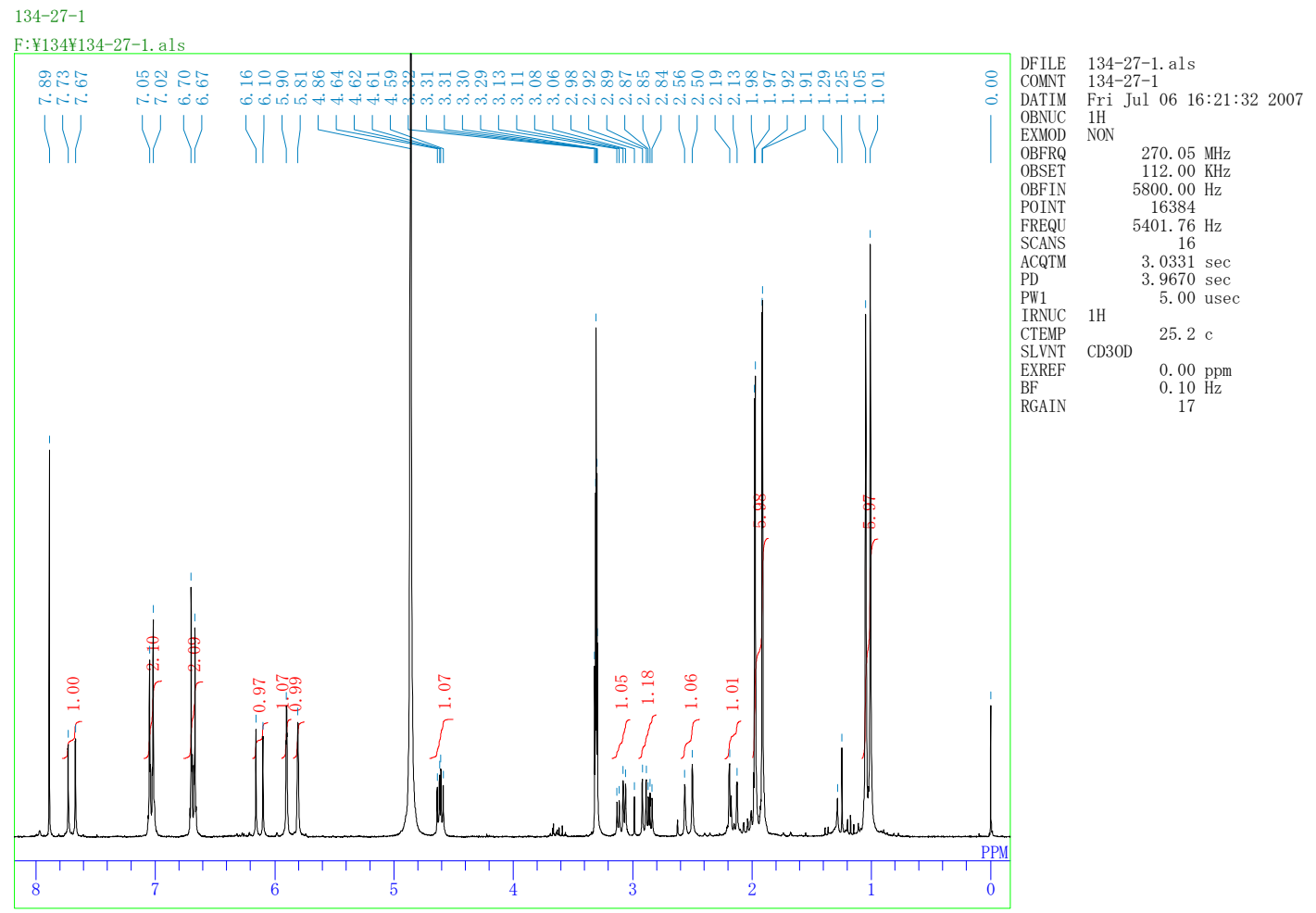

ABA-Cys

fr. 9

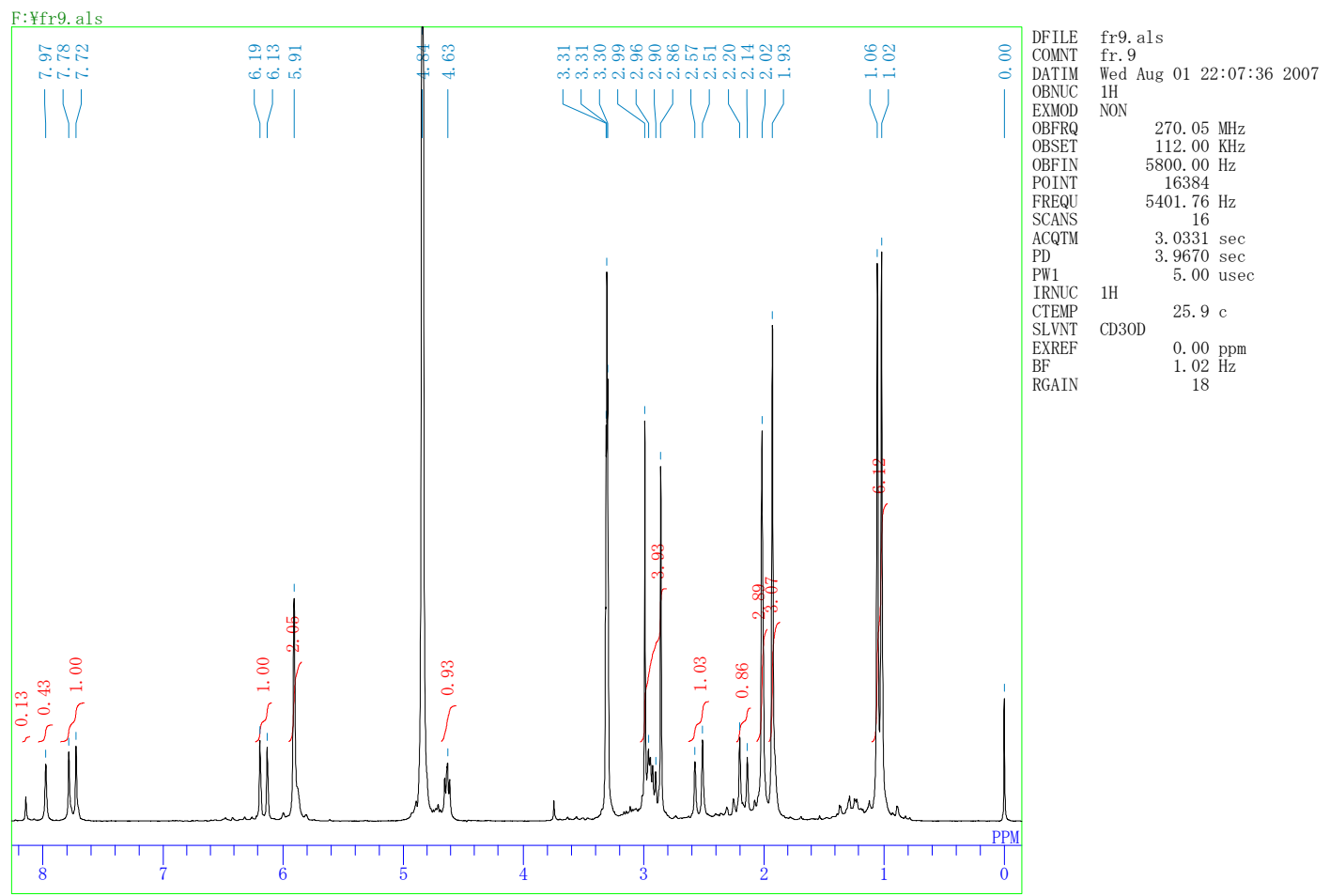




\section{ABA-Lys-Me}

141-53-1

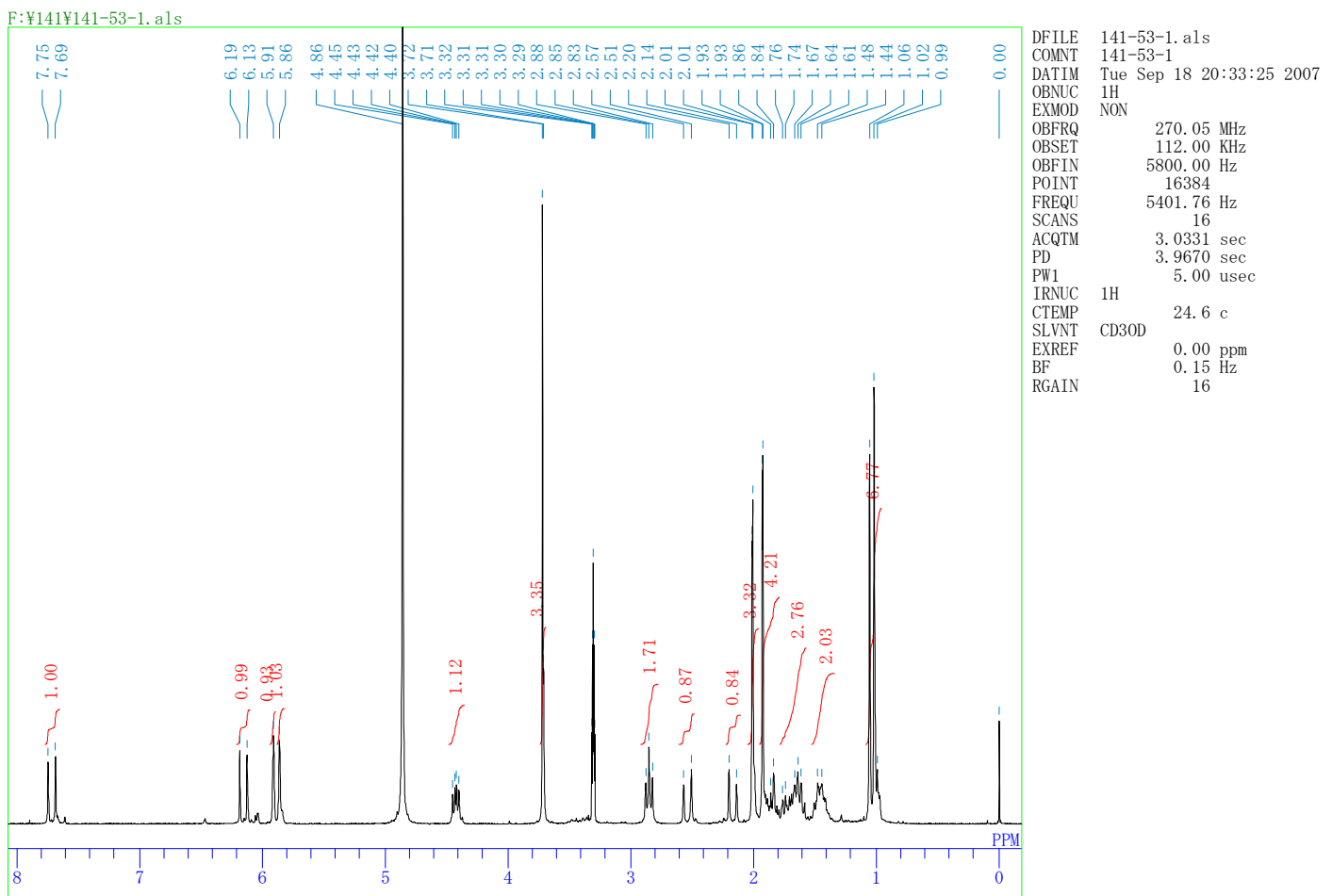

ABA-His

fr. 13

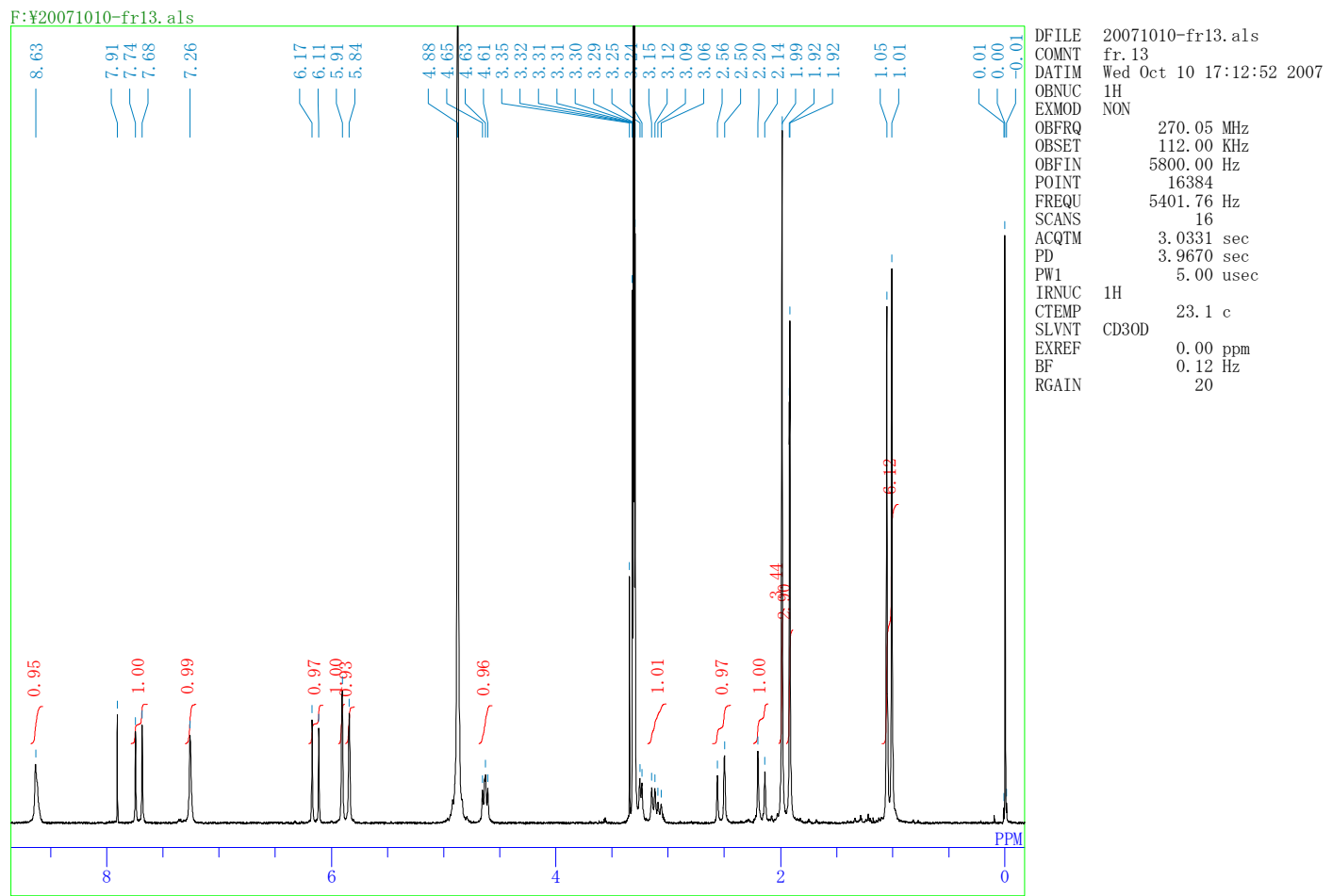




\section{A BA-Asp}

ABA-Asp

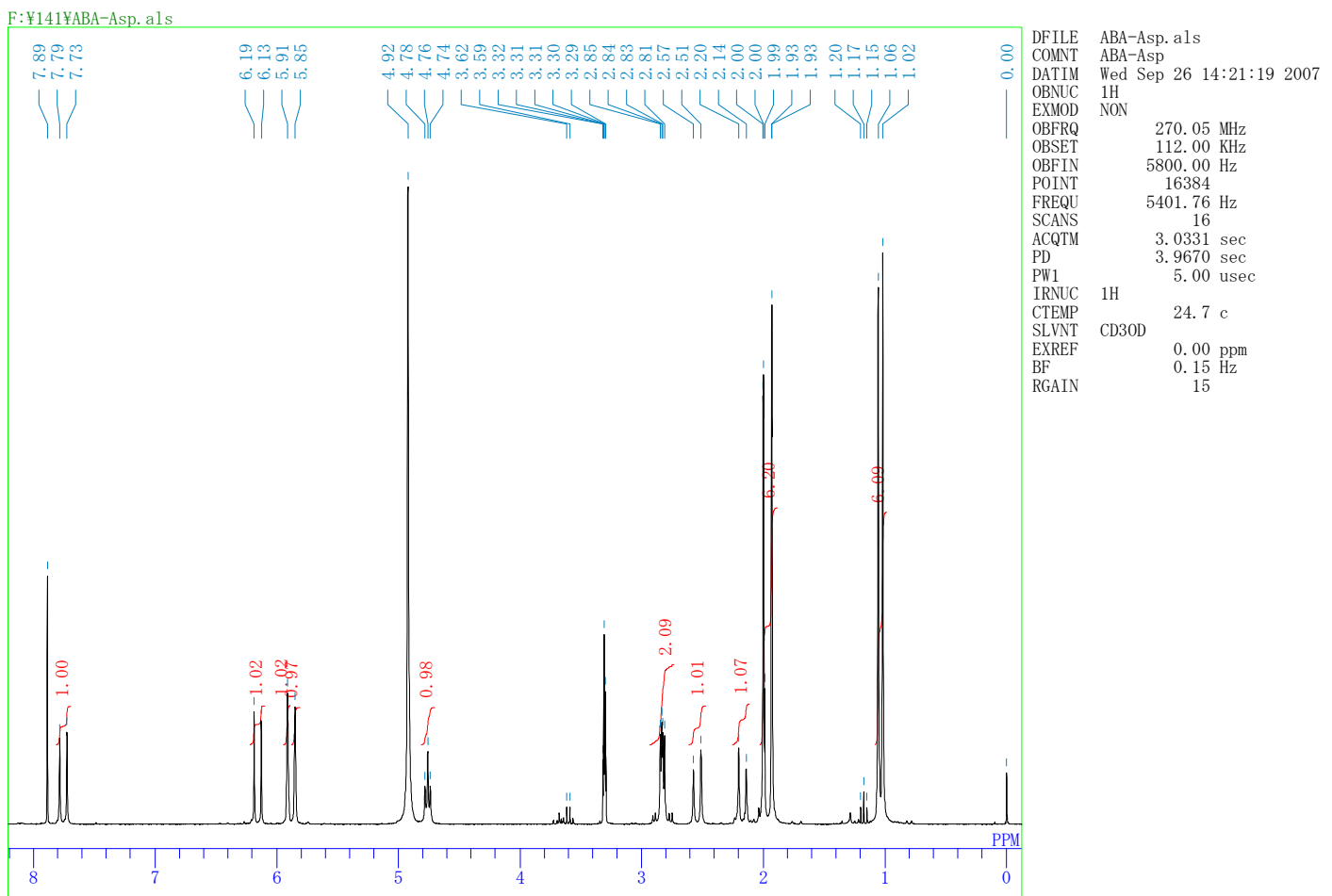

ABA-Glu

ABA-Glu

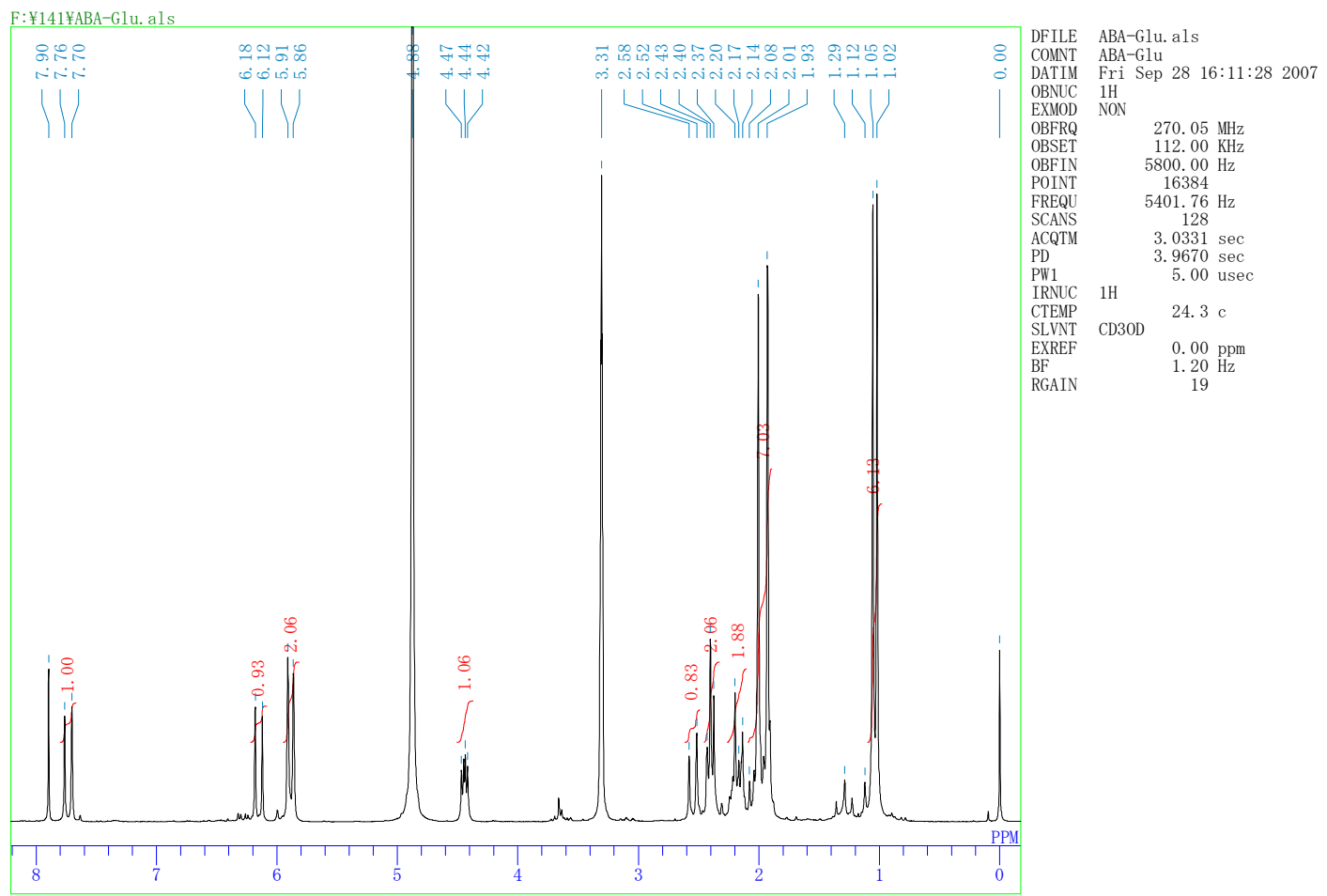


ABA- $d_{6}-\mathrm{L}-\mathrm{Ala}$

196-33-2

F: $¥$ 成田 $¥ 196-33-2$. als

8৪ㅇ

쿠 கு

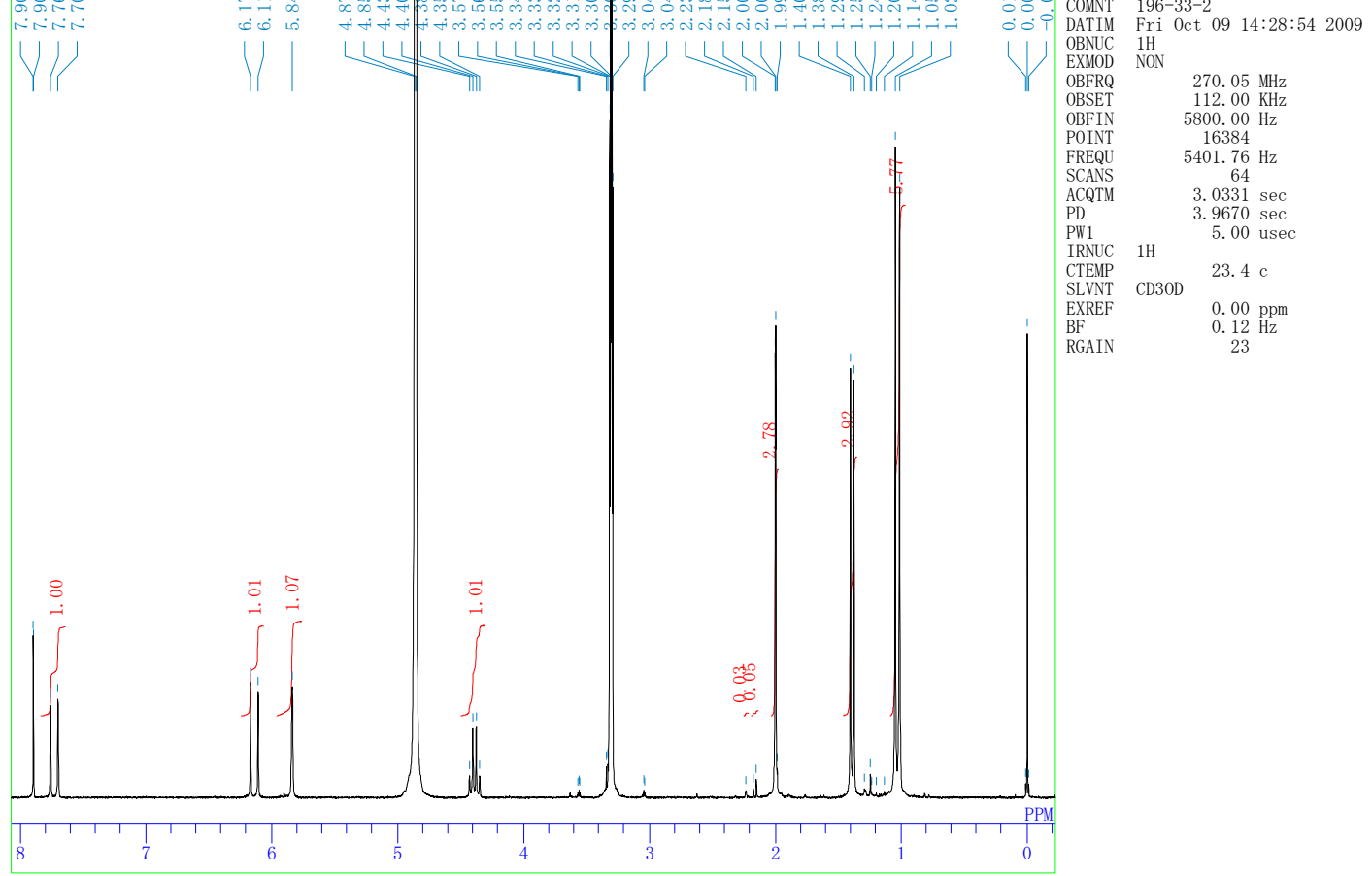

ABA- $d_{6}$-D-Ala

$196-45-2$

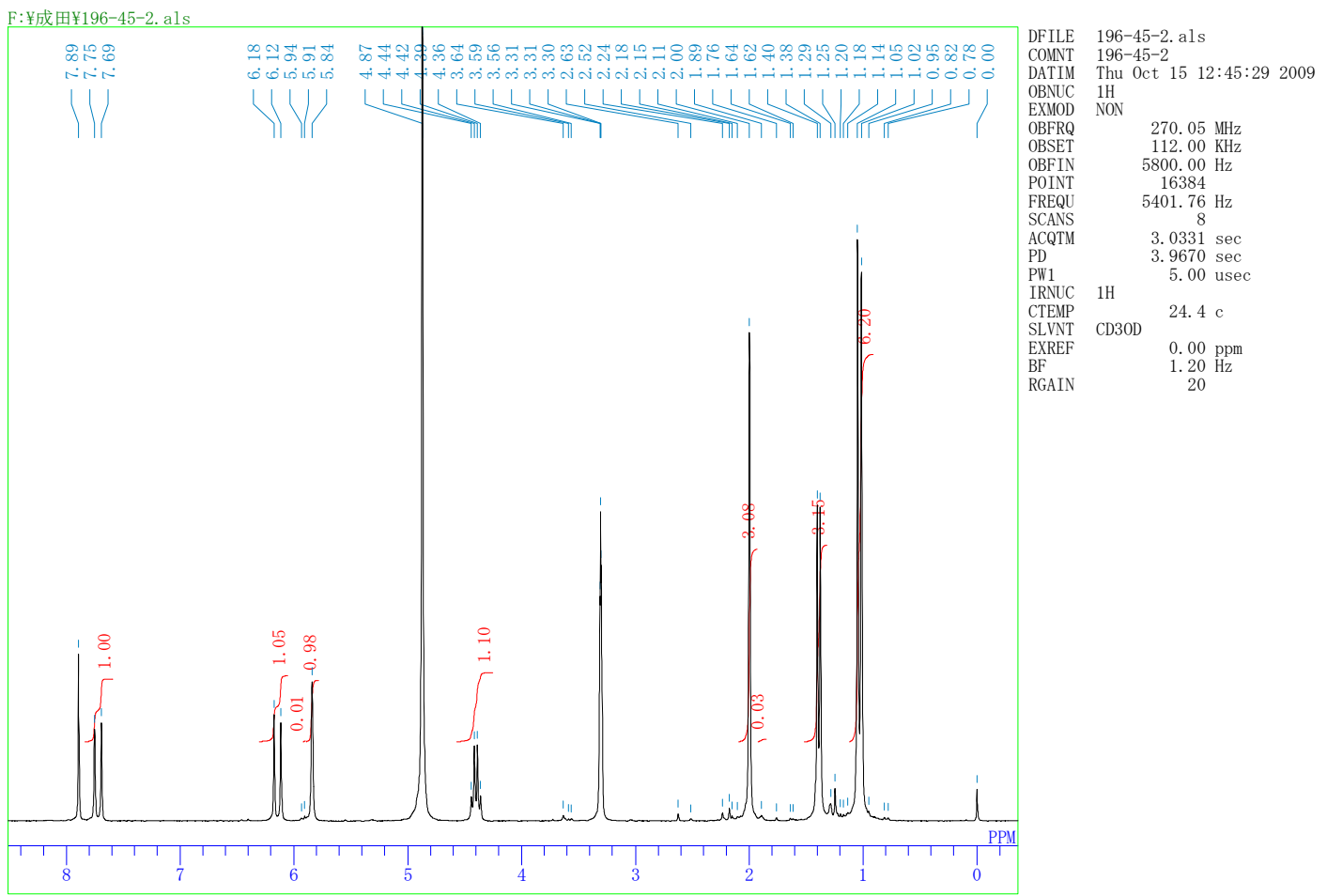


ABA-NHCH 3

150-39-1

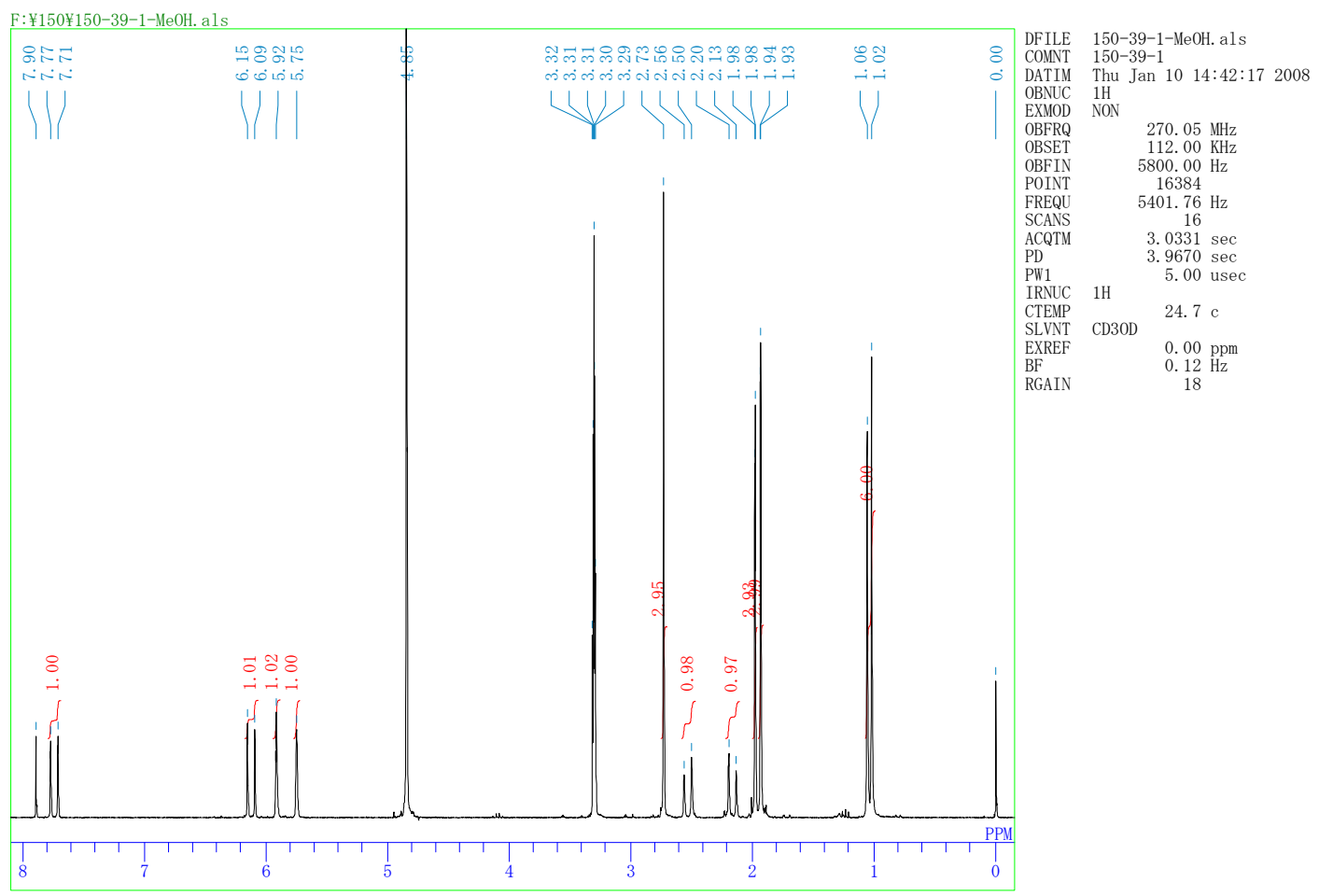

